\title{
Mineral medicine: from traditional drugs to multifunctional delivery systems
}

\author{
Xiaoqing Zhong ${ }^{1,2+}$, Zhenning $\mathrm{Di}^{1,2+}$, Yuanxin X $\mathrm{u}^{1,2+}$, Qifan Liang ${ }^{1,2}$, Kuanhan Feng $^{1,2}$, Yuting Zhang ${ }^{1,2}$, \\ Liuqing $\mathrm{Di}^{1,2^{*}}$ and Ruoning Wang ${ }^{1,2^{*}}$ (1)
}

\begin{abstract}
Mineral drugs are an important constituent of traditional Chinese medicine (TCM). Taking minerals that contain heavy metals as drugs is a very national characteristic part of TCM. However, the safety and scientific nature of mineral drugs are controversial owing to their heavy metals and strong toxicity. In 2000, the Food and Drug Administration (FDA) authorized arsenic trioxide (ATO) as first-line therapy for acute promyelocytic leukemia. This makes the development and utilization of mineral drugs become a research hotspot. The development of nanomedicine has found a great prospect of mineral drugs in nano-delivery carriers. And that will hold promise to address the numerous biological barriers facing mineral drug formulations. However, the studies on mineral drugs in the delivery system are few at present. There is also a lack of a detailed description of mineral drug delivery systems. In this review, the advanced strategies of mineral drug delivery systems in tumor therapy are summarized. In addition, the therapeutic advantages and research progress of novel mineral drug delivery systems are also discussed. Here, we hope that this will provide a useful reference for the design and application of new mineral drug delivery systems.
\end{abstract}

Keywords: Mineral drug, Traditional preparation, Novel drug delivery system, Active ingredient

*Correspondence: diliuqing@nujcm.edu.cn; ruoningw@njucm.edu.cn; ruoningw@163.com

${ }^{\dagger}$ Xiaoqing Zhong, Zhenning Di and Yuanxin Xu contributed equally to this work

${ }^{1}$ College of Pharmacy, Nanjing University of Chinese Medicine, Nanjing 210023, China

Full list of author information is available at the end of the article permits use, sharing, adaptation, distribution and reproduction in any medium or format, as long as you give appropriate credit to the original author(s) and the source, provide a link to the Creative Commons licence, and indicate if changes were made. The images or other third party material in this article are included in the article's Creative Commons licence, unless indicated otherwise in a credit line to the material. If material is not included in the article's Creative Commons licence and your intended use is not permitted by statutory regulation or exceeds the permitted use, you will need to obtain permission directly from the copyright holder. To view a copy of this licence, visit http://creativecommons.org/licenses/by/4.0/. The Creative Commons Public Domain Dedication waiver (http://creativecommons.org/publicdomain/zero/1.0/) applies to the data made available in this article, unless otherwise stated in a credit line to the data. 


\section{Graphical Abstract}

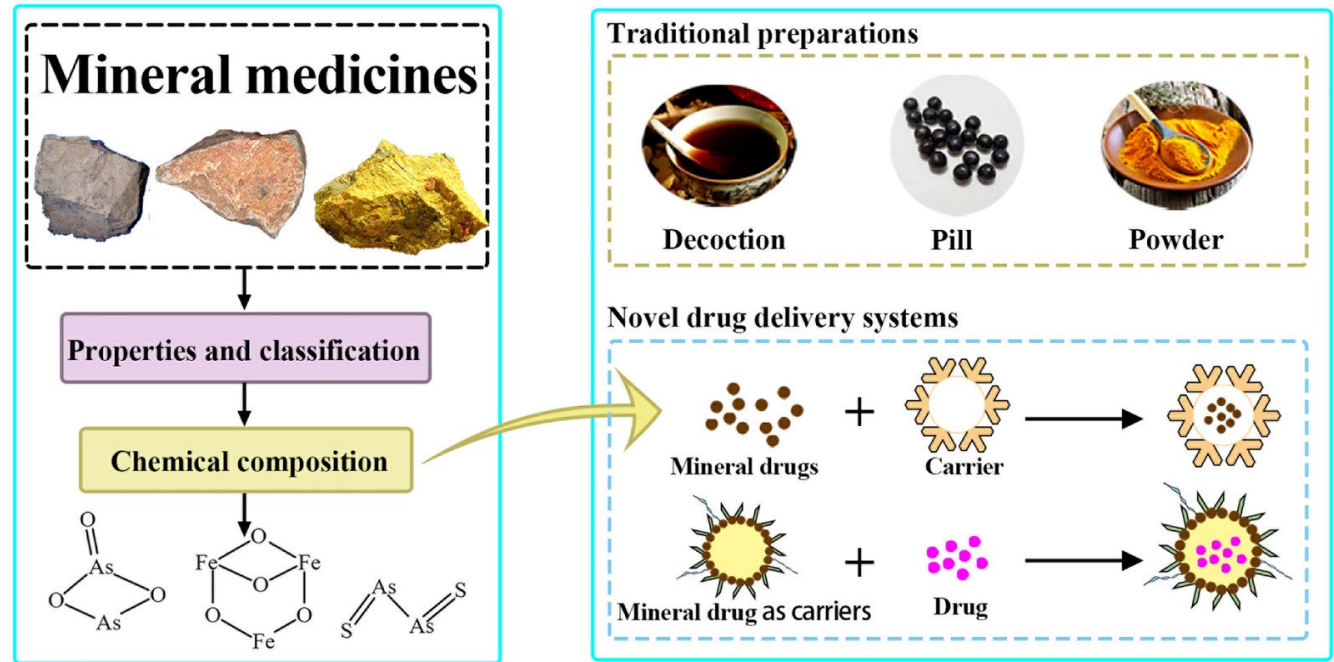

\section{Background}

Minerals are rich in resources in China and have significant curative effects as medicines, and are a unique component of traditional Chinese medicine (TCM). The research and utilization of mineral drug resources have a history of more than 2000 years. As early as the Springautumn Warring period, there were two kinds of mineral drugs used to treat diseases among the 122 kinds of drugs. Fifty-two disease prescriptions, the earliest existing medical classic, recorded the clinical application of
20 kinds of mineral drugs, such as realgar, cinnabar, and saltpeter. With the in-depth study of TCM, mineral medicine has gradually become a major research hotspot of drug development and application at home and abroad. Mineral medicine is a general term for natural minerals with medicinal value, mineral processed products and fossils of animals or animal bones. Among them, natural minerals such as cinnabar, gypsum, calamine, and ochre. The processed products of minerals include light powder, red powder, autumn stone and so on. Fossils of animals

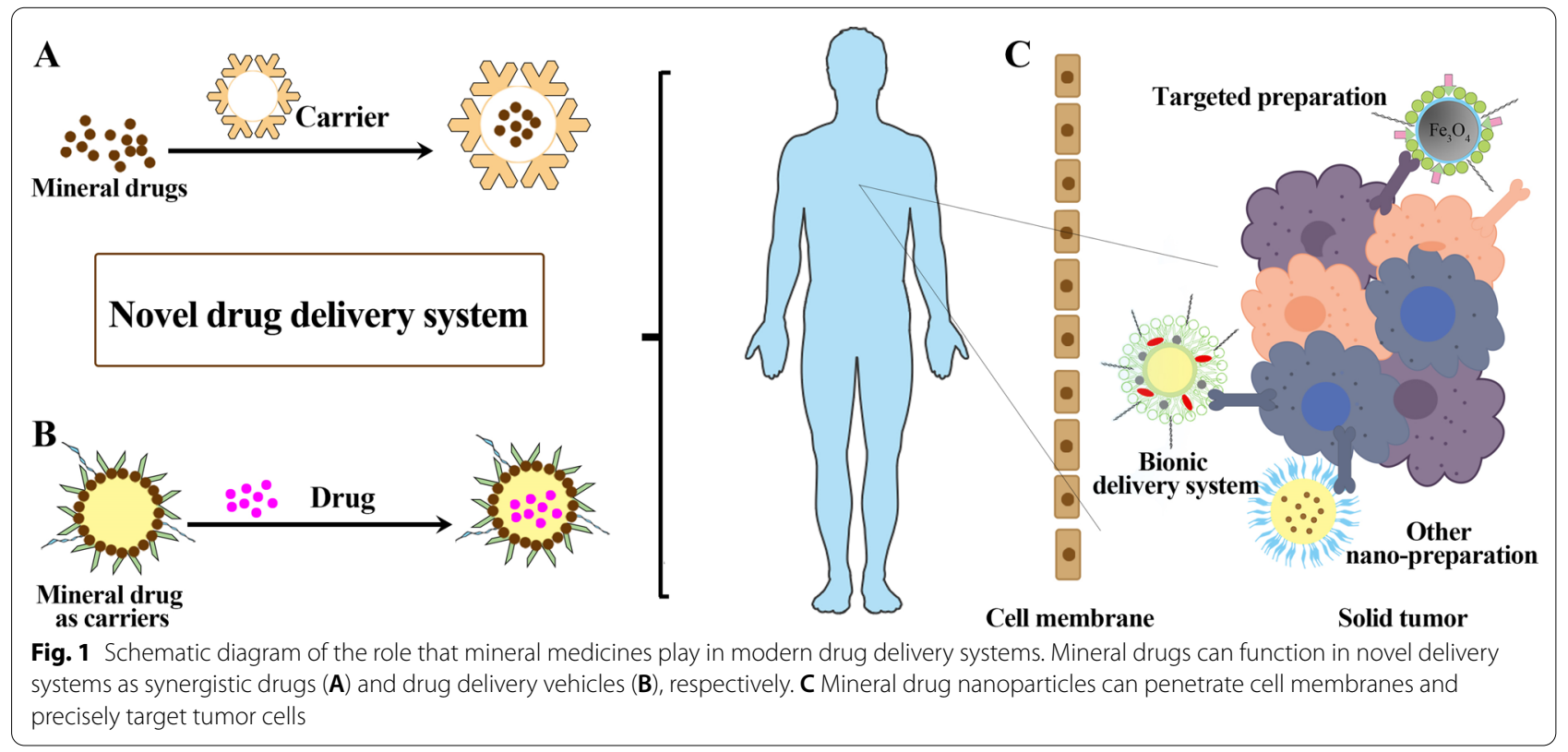


or animal bones include keels, stone swallows, etc. [1-3]. Modern pharmacology found that many mineral drugs have a good curative effect for a variety of malignant tumors, such as arsenic and cinnabar. Yet, the practical trial of mineral drugs is curbed on account of the problems of inferior water solubility, high content of heavy metals, and severe toxicity. Recently, the research of some novel drug delivery techniques has brought opportunities for the development and adoption of mineral drugs.

Many studies focus on the drug delivery systems loaded mineral drugs, to acquire advanced efficacy and decreased toxicity with less adverse reactions. As shown in Fig. 1A, B, mineral drugs usually play a significant role in tumor therapy in the forms of drugs or carriers. Figure $1 \mathrm{C}$ shows that mineral drug nanoparticles can accurately penetrate the cell membrane to the tumor tissues. Ettlinger et al. designed a kind of zeolitic imidazolate skeleton- 8 as the $\mathrm{pH}$-responsive messenger of arsenic trioxide (ATO), which has high remedy loading and significant $\mathrm{pH}$ triggered release behavior at the same time [1]. It has been proved to be a promising candidate material for transporting arsenic compounds. According to literature reports polylactic acid/magnetic compound nanoparticles, liposome complexes, amino acid, and other materials are used to deliver ATO to revamp the cure of arsenate in carcinoma treatment [2-4]. Another typical mineral drug is magnetite, which is mainly composed of $\mathrm{Fe}_{3} \mathrm{O}_{4}$. Rayegan et al. loaded cephalexin (CPX) on magnetic nanoparticles encapsulated in basilicum seed mucilage (BSM) to prepare the complex with more gradual and sustained drug release $\left(\mathrm{Fe}_{3} \mathrm{O}_{4} @ \mathrm{BSM}-\mathrm{CPX}\right)$. With the help of magnetic targeting of $\mathrm{Fe}_{3} \mathrm{O}_{4}$, a further drug send system was developed, and its antibacterial ability of the complex was significantly increased [5].

This review systematically summarizes the latest research on the enhancement of the curative effect of mineral drugs in the drug delivery system. Of note, the classification and active components of mineral drugs are introduced to promote the understanding of mineral drugs. More importantly, the modern pharmacological effects of mineral drugs are described in detail. Based on the active components and pharmacological activities of mineral drugs, the recent research progress of mineral drugs combined with novel drug delivery systems is highlighted. In the end, some critical challenges in the research of mineral drugs based on drug loading systems are discussed to provide a reference for the future development of mineral medicines.

Properties and classification of Chinese mineral medicine Mineral drugs of TCM include original minerals (cinnabar, gypsum, calamine, etc.), processed products with minerals as raw materials (calomel, mirabilite, etc.), fossils of animals, or animal bones (fossil fragments, dragon teeth, etc.). It is a part of the characteristics of Chinese medicine and has an idiographic function in the progress of TCM [6]. With the development of the internationalization of TCM, the research of traditional mineral medicines is gradually in-depth and extensive. In this section, we will outline the properties and classification of mineral drugs.

\section{Mineral properties of Chinese medicine}

Medicate with minerals, especially mineral medicine containing heavy metals, is a very extraordinary part of TCM. In the second century before Christ, mercury could be refined from cinnabar. In Song Dynasty, there are 139 kinds recorded in Zheng Lei Ben Cao and 222 kinds recruited in the Compendium of Materia Medica. Mineral drugs are abundant in resources and used widely. Figure 2 vividly shows the development of mineral medicine for thousands of years, indicating that mineral medicine has always been a part of TCM.

Except for a few natural elements, mineral drugs are mostly composed of a lot of compounds. Each mineral has certain physical and chemical properties. The knowledge of mineral medicine is generally identified from its appearance, physical and chemical properties, and microscopic observation. The appearance properties of mineral medicine include color, streaks, texture, smell, hardness, cleavage, fracture, magnetism, and specific gravity. Of note, the pyrite is dense, massive, and has green-black or red-brown streaks. Meanwhile, magnetite, commonly used in Chinese medicine for tranquillization, is gray-black, irregular block, metallic luster. Chlorite schist is greenish-black with glassy luster, and its cross-section is lamellar. Among them, mineral medicine has its inherent streak color. The streak color is the color of the powder trace left by the mineral after scratching on the white wool porcelain plate. The streak color may be different from the color of the mineral itself. For example, the surface of the pyritum is bright yellow, and the streak color is green-black to brown-red. In addition, microscopic identification can more accurately identify drugs from the optical properties of mineral drugs. At present, the identification of mineral medicines is gradually inclined to rely on various modern scientific and technological means, such as X-ray diffraction, electron microscopy, atomic absorption spectroscopy, thermal analysis, phase analysis, infrared spectroscopy, and nuclear magnetic resonance.

In recent years, the pharmacodynamic research of traditional Chinese medicine decoction has become more and more in-depth. Some studies believe that the metal ions in mineral medicines may participate in the formation of nanostructures of other ingredients 


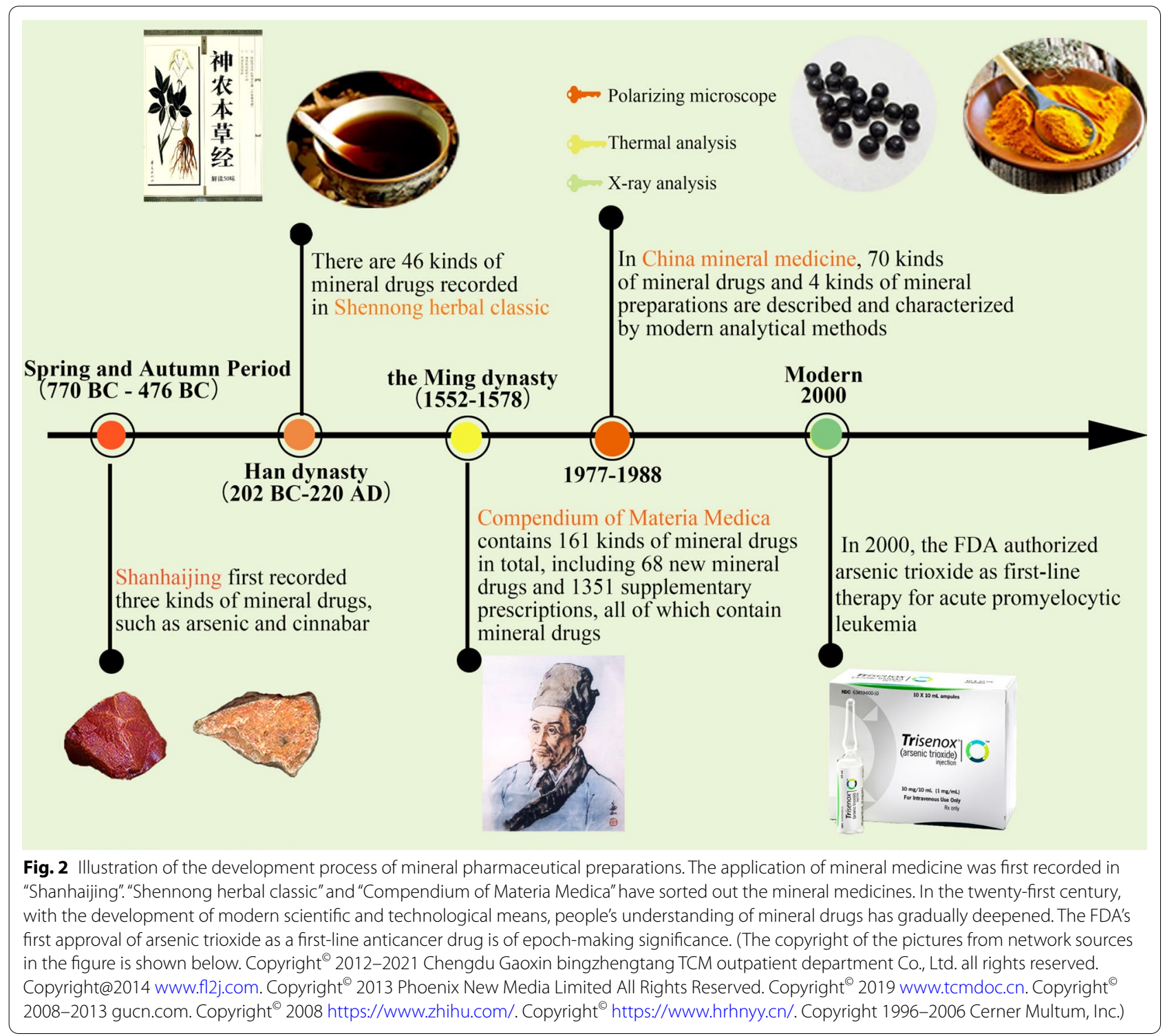

in the decoction through coordination, forming selfassembled nanoparticles, thus exerting their medicinal effects. With the expansion of mineral drug research, many mineral nanoparticles have attracted extensive attention in the fields of bioengineering, biomedicine, and food analysis because of their unique properties [7]. For example, $\mathrm{Fe}_{3} \mathrm{O}_{4}$ nanoparticles have the properties of superparamagnetic, high external area, and low toxicity, which are widely used to enhance medicament efficacy and improve cancer treatment effects in the magnetic targeted delivery systems $[8,9]$. Table 1 summarizes the classification and efficacy indications of mineral drugs in TCM.

\section{Common classification of mineral drugs}

In traditional Chinese medicine theory, mineral medicines can be divided into five categories according to their properties and functions: sedation and tranquility, tourniquet hemostasis, detoxification, vigorous purification of drainage, and insecticide. For example, cinnabar and magnetite have a sedative effect, and ochre has a hemostatic effect. At present, the modern classification of mineral medicines is mostly classified according to the type of anion or cation that is the main component of the mineral. The Chinese Pharmacopoeia adopts anion classification. For example, cinnabar and realgar are sulfur compounds, gypsum and strange stone are sulfates, 


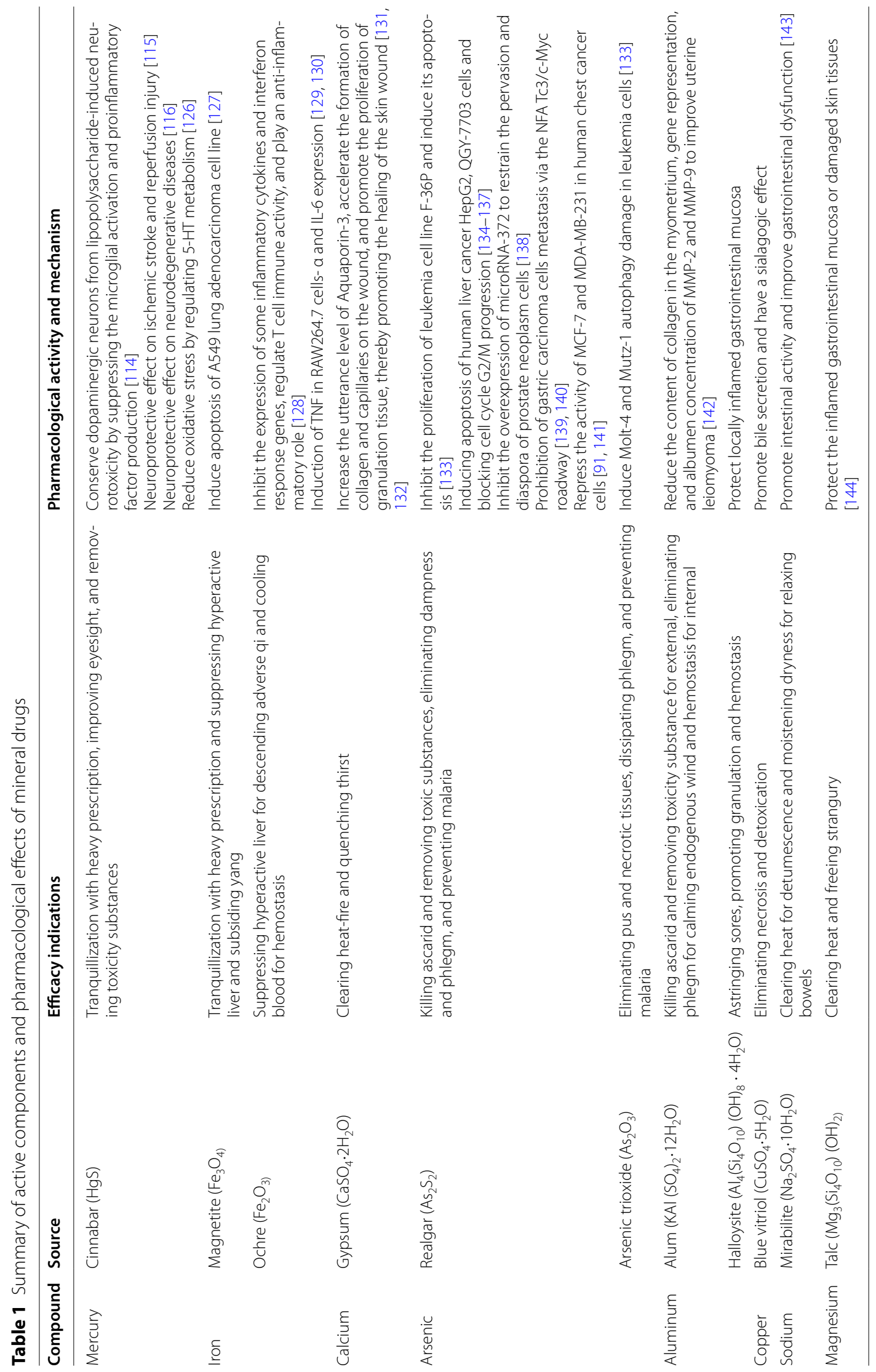


calcium amines are carbonates, magnetite and ochre are oxides, and calcium amines are halides. Cation classifications include mercury compounds, arsenic compounds, lead compounds, iron compounds, calcium compounds, aluminum compounds, copper compounds, sodium compounds, and magnesium compounds $[4,5]$.

\section{Chemical constituents of minerals in traditional Chinese medicine}

Most mineral drugs are compounds containing heavy metal elements. The main ingredients include arsenic, lead, mercury, copper, iron, magnesium, aluminum, calcium, silicate, sulfate, and other ingredients. These ingredients include trace elements required by the human body and have an impact on human health, which has attracted wide attention from researchers.

\section{Chemical composition and pharmacological action of mineral medicine}

Many mineral drugs have significant pharmacological activity. Copper, iron, etc. are common metal elements and trace elements necessary for the human body. Lack of it can cause physiological dysfunction and cause disease. Copper has certain effects on cardiovascular, bone marrow, central nervous system, and red blood cell production. Copper participates in the body's biochemical functions such as oxidative phosphorylation, free radical detoxification, melanin synthesis, catecholamine metabolism, connective tissue cross-linking, blood coagulation, and hair formation. Azurite ore, chlorocopper ore, and bornite ore can all be used as medicine. $\mathrm{CuSO}_{4} \cdot 5 \mathrm{H}_{2} \mathrm{O}$ is the main component of chalcogenide and has a good antibacterial effect. Studies have shown that, compared with ordinary copper oxide, nano-copper oxide has superior properties such as surface effect, quantum size effect, volume effect, and macroscopic quantum tunneling effect $[10,11]$. Iron is the most abundant and important hematopoietic element in the human body. Iron-containing drugs mainly exist as iron elements, iron oxide, iron sulfide, or iron sulfate. Mineral drugs containing iron and its compounds are clinically used to treat convulsions, swelling toxins, iron-deficiency anemia, and various causes of blood deficiency and blood deficiency. Among them, magnetite mainly contains iron tetroxide, ochre mainly contains iron trioxide, and pyrite mainly contains iron disulfide. With the research of nanomedicine, magnetic nanoparticles have shown positive advantages in biomedicine and drug delivery [12-15].

Calcium and sodium are also common mineral medicine ingredients. Calcium-containing mineral medicines mainly contain oxides, carbonates, and calcium fluoride as their main active ingredients. Calcium-containing mineral drugs have a wide range of clinical applications in gynecological diseases. In addition, calcium mineral medicine also has a special anti-convulsant and soothing effect and is clinically used for epileptic mania. For example, the main component of amethyst is $\mathrm{CaF}_{2}$, which can excite the central nervous system and ovarian secretion function. Sodium-containing mineral drugs are mainly used clinically to reduce local leukocyte infiltration, regulate body immunity, and prevent postoperative infections. For example, borax mainly contains sodium tetraborate, which has antiseptic and anticonvulsant effects. Glauber's salt mainly contains water-containing sodium sulfate, which has anti-inflammatory, anti-bacterial, and laxative effects.

Mineral medicine also contains non-metallic compounds, such as talc, white quartz, and other traditional Chinese medicines containing silicon. Talc is a silicate mineral, mainly containing hydrous magnesium silicate, which has the function of protecting skin and mucous membranes and antibacterial. The main component of white quartz is silica, which has sedative, calming, antitussive and anti-asthmatic effects. In addition, silica, the main component of the quartz photo album, can be used as a load-bearing coating for various nano-drugs, exaggerating the stability of the nano-particles and increasing the efficacy of the nano-particles [16-19].

\section{Toxicity of mineral medicine}

Some toxic heavy metals also have medicinal value, such as mineral medicines containing mercury, lead, gold, and silver. For example, cinnabar is a natural ore of mercury sulfide. $\mathrm{HgS}$ is a substance that is hardly soluble in water and organic solvents. Under the action of acid effect and complexing effect in the human body, it can dissociate and complex reaction with amino acid and other biological molecules to form complexes with strong physiological activity and less toxicity. Therefore, cinnabar can act on the central nervous system, with hypnotic, brain protection, anti-fear, anti-anxiety, and anti-convulsant effects. Realgar mainly contains arsenic sulfide, which is antibacterial and resistant to blood-sucking worms. The main component of arsenic is arsenic trioxide, which can be used to treat leukemia and inhibit tumor angiogenesis [6].

Mercury is a toxic metal commonly found in mineral medicines. Inorganic mercury, elemental mercury, and methylmercury have strong binding to human serum proteins, and interfere with cell metabolism by binding to sulfhydryl groups of receptor proteins or cellular enzymes, thereby inducing cell death. Mercury can accumulate in vital organs such as the liver, kidneys, brain and heart with blood circulation. Arsenic also has significant cytotoxicity, and arsenic oxide can specifically damage pyruvate dehydrogenase in 
mitochondria, hindering both aerobic and anaerobic respiration. The cells thus suffer from acidosis and undergo rapid apoptosis. Long-term consumption of large amounts of realgar can produce obvious toxic reactions. One of the mechanisms responsible for the nephrotoxicity of realgar may be the accumulation of renal copper. However, there are also clinical methods for treating malignant diseases by inducing rapid apoptosis of cells.

Since the safety of toxic mineral drugs has always been controversial, there have been many cases of oral or topical poisoning of mineral drugs at home and abroad. Therefore, the Pharmacopoeia of the People's Republic of China has strict regulations on the use of toxic mineral drugs. For example, the incidence of adverse reactions caused by cinnabar increases with the increase of the dosage and the prolongation of the medication time. Therefore, cinnabar should not be taken in large quantities or a small amount for a long time, 0.1-0.5 g per day, mostly in pills and powder, not in decoctions, and appropriate for external use. The light powder should not be used in excess. It should be used with caution for internal use and appropriate amount for external use. In addition, it is also necessary to formulate corresponding drug restrictions for specific groups, such as pregnant women, children, etc., should pay attention to the contraindications and limits when using toxic mineral drugs.

The minerals of most Chinese medicines contain a mixture of many heavy metal elements. Most metal mineral drugs are hard in texture and difficult to be crushed into medicines. Therefore, they are usually processed by methods such as high-temperature calcination, the addition of auxiliary materials, grinding, water jetting, and purification before clinical application. The processing steps can also reduce the side effects of toxic mineral drugs. The composition and content of mineral medicines processed from the same mineral raw materials are different, which will lead to changes in their pharmacological effects. For example, the main component of gypsum is $\mathrm{CaSO}_{4} \cdot 2 \mathrm{H}_{2} \mathrm{O}$, which has a strong heat-clearing and clearing ability, while forged gypsum mainly contains calcium sulfate, which has a stronger hemostatic effect. The iron-containing mineral drug substitute ocher is calcined and quenched with vinegar to make the texture crisp and easy to crush. Among them, the content of toxic metals such as arsenic, lead, and mercury is significantly reduced, while the dissolution of iron, calcium, magnesium and other elements is significantly increased. The acute toxicity of realgar processed with yogurt was significantly reduced, but its analgesic and anti-inflammatory effects were the same as those of the raw product [7-9].

\section{Discussion on traditional preparations of mineral drugs}

The medicament forms of TCM are an extremely characteristic part of the Chinese medicine culture. Meanwhile, it is also the product of TCM syndrome differentiation theory. The dosage forms of drugs always change with the nature of ailments and the physicochemical properties of the mineral drugs themselves. The great majority of mineral drugs are heavy and venomous. In traditional applications, most of them are prepared into pills, soups, and powders for the treatment of some difficult and miscellaneous diseases. Starting from the traditional dosage forms of TCM, this section discusses the application of mineral drugs in traditional medicine prescriptions and patent medicines. Table 2 shows detailed information on traditional mineral preparations.

\section{Traditional decoction of mineral medicine}

The most scripture and oldest form of TCM is decoction. It has the characteristics of high-speed absorption and swift function. Mineral drugs are usually decocted with the pattern of pre-frying to fully stimulate the active ingredients. The reason is that most of the minerals are hard to dissolve or contain certain toxicity. Moreover, since the longtime of decocting, it can greatly reduce the toxicity. Baihu decoction (BHD) has the effect of clearing away heat and promoting body fluid with the gypsum as its sovereign drug. Modern research demonstrates that the material foundation of BHD is calcium ion in gypsum, in which $83.25 \% \mathrm{Ca}$ exists in the free state and $23.79 \%$ Ca retains in soluble filtrate in the organic form [20]. By reducing the levels of interleukin-1 $\beta$ (IL$1 \beta)$ and tumor necrosis factor $\alpha$ (TNF- $\alpha)$ in serum and hypothalamus of rabbits which was injected lipopolysaccharide, the BHD has an obvious antipyretic effect [21]. Therefore, BHD can become a natural anti-fever and anti-inflammatory candidate. BHD is diffusely used in the clinic to heal infectious diseases, viral poor and high fever, acute cerebral hemorrhage, diabetes, acute hyperglycemia, and rheumatoid arthritis [22, 23]. As shown in Table 2, Dachengqi decoction (DCQD) is a classical Chinese medicine recipe for curing constipation with excess heat. Mirabilite is one of the significant minister medicines, with positive heat-clearing and catharsis effects [24]. DCQD is constantly used in clinical therapy of acute cholecystitis, acute appendicitis, acute simple intestinal obstruction, and so on. It is reported that DCQD contributed with conventional therapy has a significant effect in the curing of hyperlipidemia acute pancreatitis [25]. Network pharmacology research found that DCQD on the therapeutics of pancreatitis may be achieved via two-way regulation, including anti-inflammatory and antioxidant effects, pro-apoptosis, and regulation of pancreatic secretion. This process involves numerous 


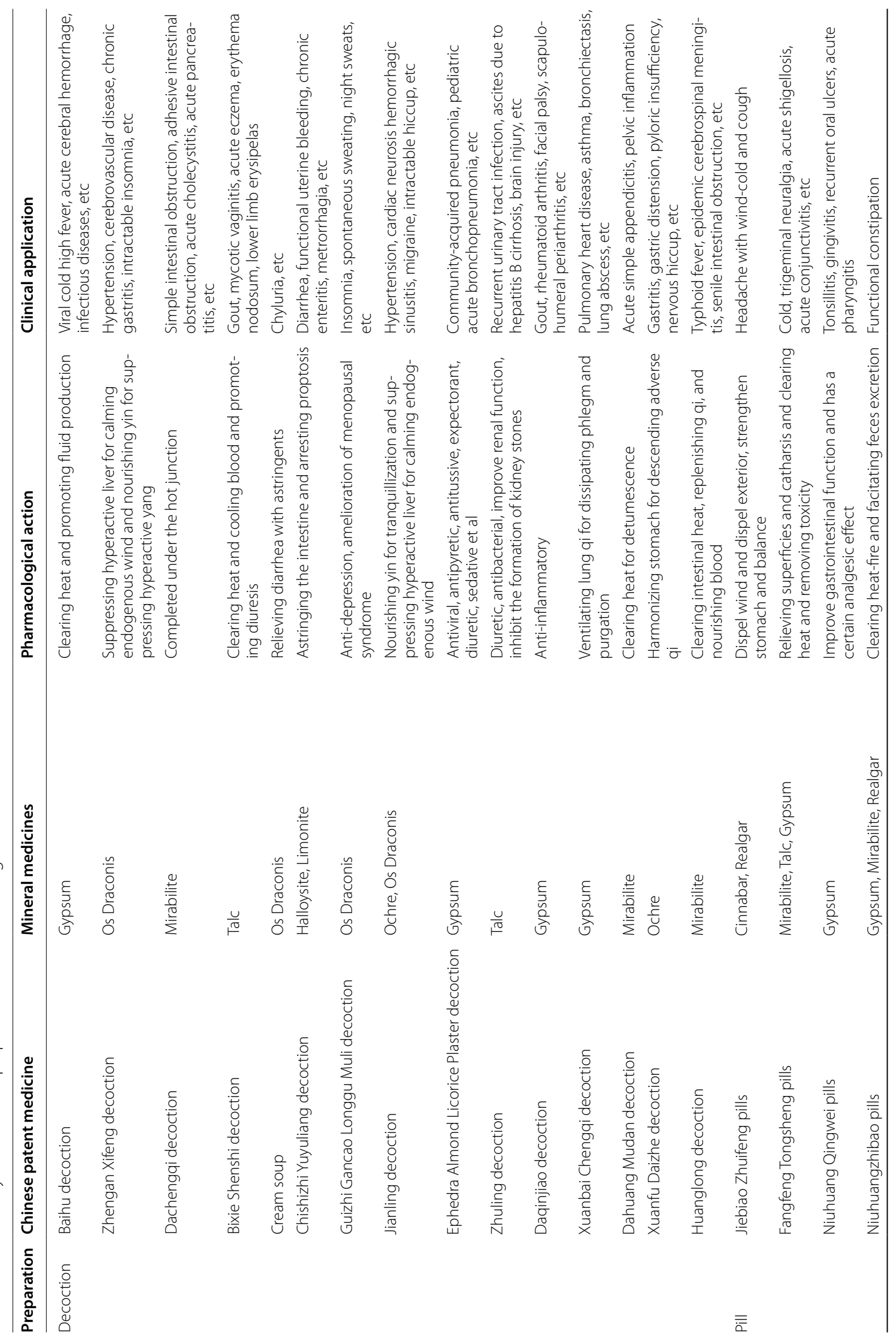




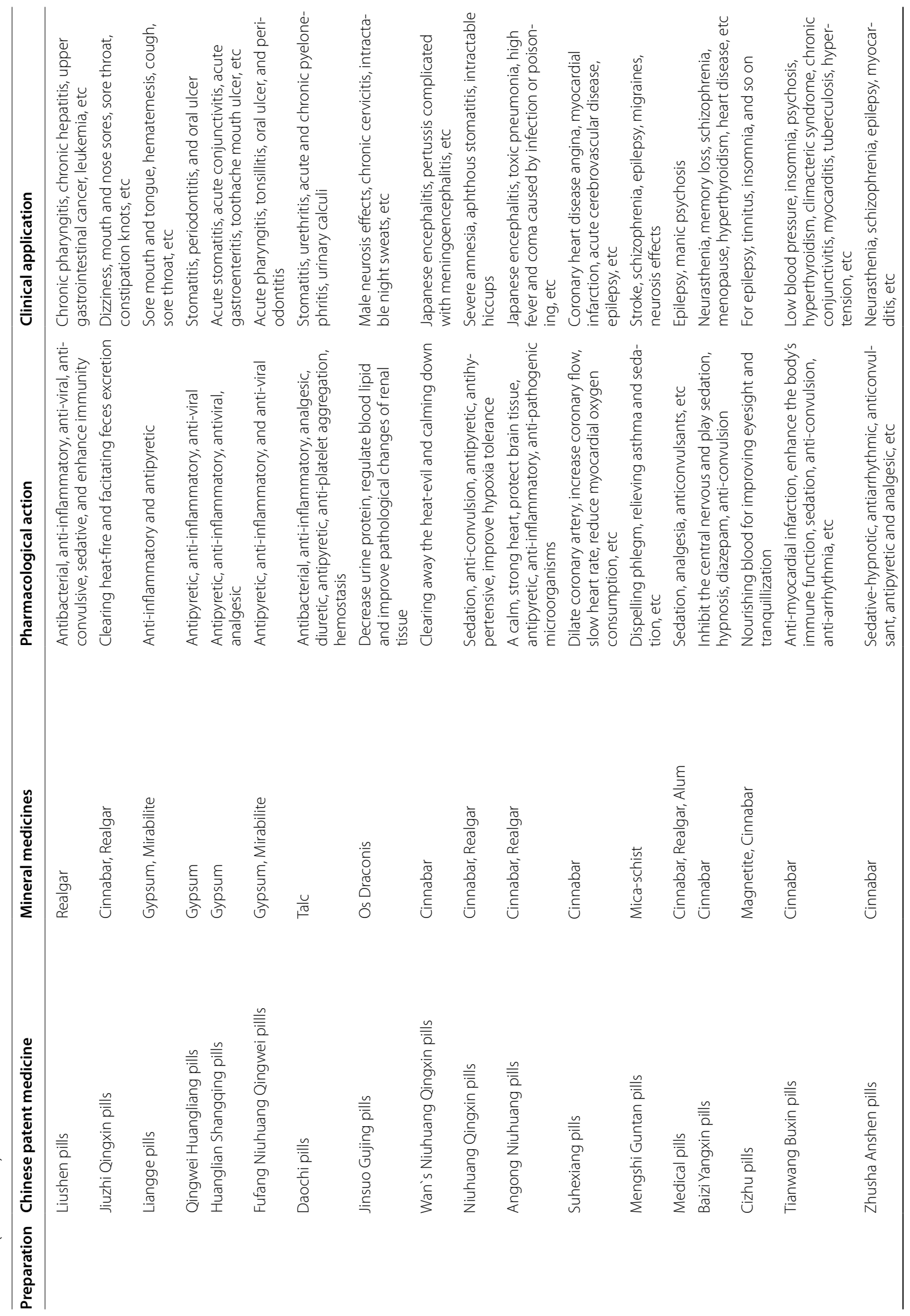




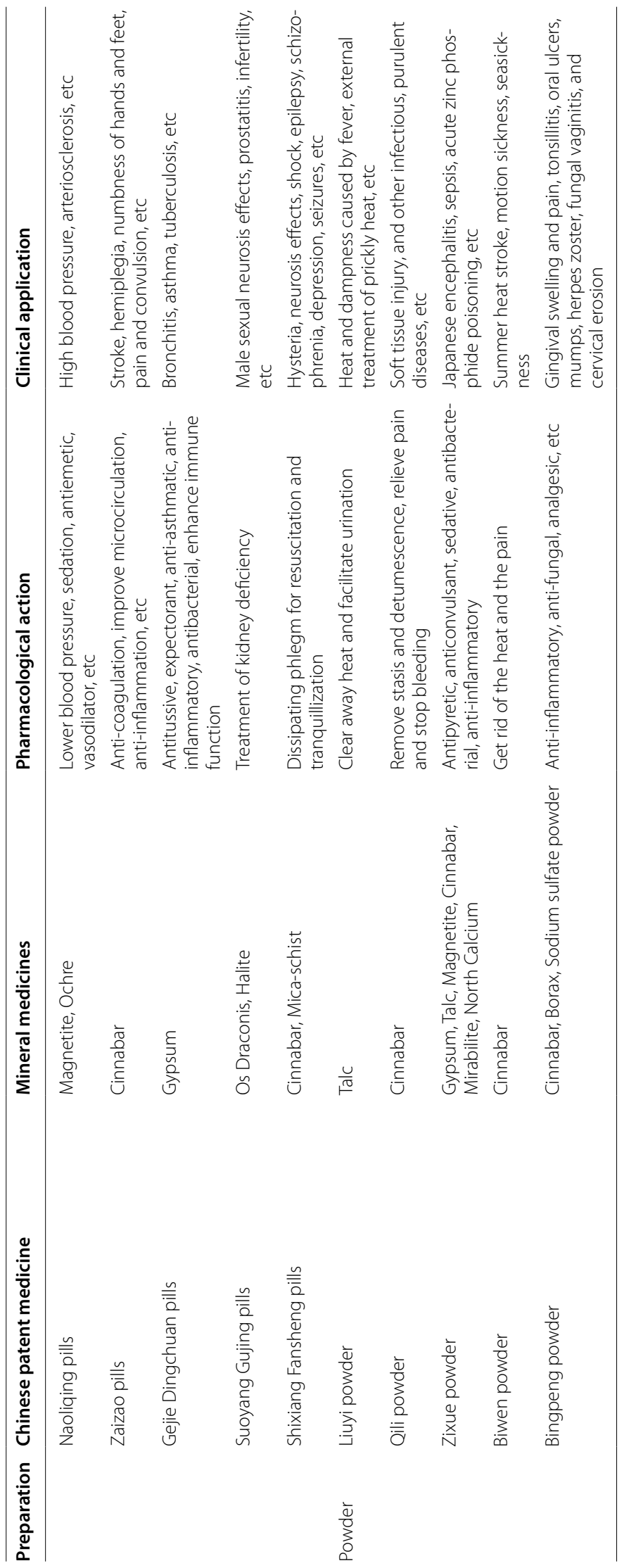


pathways and signals, such as interleukin-17 (IL-17), tumor necrosis factor (TNF), and nuclear factor kappa B, but the concrete mechanism of DCQD needs further study [26-28]. In clinical application, DCQD also illustrates the superiority in treating apoplexy, cerebral hemorrhage, and other diseases. From 296 active components of DCQD, 52 linchpin elements related to stroke were selected, which are mainly involved in the regulation of oxidative stress, lipid metabolism, and anti-inflammation [29]. Zeng et al. treated intracerebral hemorrhage model rats with DCQD for 7 days and found that the number of M2 microglia and N-methyl-D-aspartate receptors in the DCQD group increased significantly through the behavior test and protein subcomponent analysis. In this regard, the authors suggest that the mechanism may be through inhibiting mitogen-activated protein kinase and activating M2 microglia to protect rats with cerebral hemorrhage [30].

\section{Prescription preparation of mineral medicine}

Based on the boundedness of clinical application of decoction, pills play an important role in mineral drug preparations. The reason is the easy storage, long efficacy, and convenient use of pills. The great majority of pills are designed for the therapeutics of some chronic and debilitating diseases, such as Zhusha Anshen pills containing $\mathrm{HgS}$, Cizhu pills containing $\mathrm{Fe}_{3} \mathrm{O}_{4}$, etc. And they all possess the characteristics of slow absorption, lasting curative effect, for epilepsy, insomnia, tinnitus has a superior therapeutic effect. Some of the pills prepared from certain aromatic or toxic minerals can also make it in fast treatment, such as Angong Niuhuang pills and Suhexiang pills. Suhexiang pills, which are mainly composed of cinnabar, have a positive protective effect on the acute ischemic lesion of myocardial cells. It has been found that the Suhexiang pill can dilate coronary arteries and reduce myocardial oxygen consumption [31]. Spontaneously, it is commonly used in the clinical treatment of coronary heart disease angina pectoris, myocardial infarction, and other emergencies. With the discovery of a novel drug matrix, pills have shown great potential in sustainedrelease and controlled-release preparations. Rational platform design can maximize the efficacy of mineral drugs and minimize their adverse effects.

The powder is divided into external and internal use of two, mineral medicine oral powder is generally developed into a certain size of dust and taken with water or decoction. The powder has the virtues of both decoction and pills, which have high-speed absorption and rapid activity. For some powerful and mostly toxic mineral drugs, the oral powder is generally used in some emergency treatment, and there are strict dosage restrictions. For example, the dosage of $\mathrm{HgS}$ cannot exceed $0.5 \mathrm{~g}$, and
$\mathrm{As}_{2} \mathrm{~S}_{2}$ cannot outstrip $0.1 \mathrm{~g}$. Zixue, a powder with excellent clinical curative effect, contains a large number of minerals, including gypsum, north calcitum, talc, magnetite, mirabilite, cinnabar, etc. Modern research shows that it has antipyretic, anticonvulsant, sedative, antibacterial, anti-inflammatory, and other effects, and represents excellent results in the treatment of Japanese encephalitis, epidemic cerebrospinal meningitis, sepsis, and other acute diseases. Qili powder is another typical mineral powder preparation, and cinnabar is one of the eventful components. Qili powder has the functions of removing blood stasis, detumescence, relieving pain, and hemostasis. It is commonly used in soft tissue injury, fracture, and other diseases. Consult with the traditional dosage forms of mineral drugs can provide research direction and ideas for the modern development of mineral drugs.

\section{Research on mineral drug delivery systems}

The development of nano-drug delivery systems conducts opportunities for the growth and research of TCM, especially the application of mineral drugs. And it cannot be ignored, and always has the significance of TCM in the diagnosis and treatment of diseases. Exploration of active components and pharmacological effects of mineral drugs has always been the focus of scholars ' research. Accordingly, there are a few studies on the delivery system of mineral drugs. Modern pharmacological studies have shown that mineral drugs such as arsenic trioxide and realgar have an active therapeutic effect on a variety of malignancies, including acute promyelocytic leukemia (APL), liver cancer, gastric cancer, and cervical carcinoma (Fig. 3), as shown in Table 3. Therefore, the research of mineral drugs in modern drug delivery systems is discussed in detail in this section. Firstly, the research of mineral drug delivery in nano-drug delivery was discussed from the aspects of APL, hepatocellular carcinoma (HCC), and other diseases. Then, taking magnetite as an example, the application of mineral drugs as carriers in the study of drug delivery systems is discussed.

\section{Application of mineral drugs in tumor remedy Acute promyelocytic leukemia}

Acute promyelocytic leukemia is a common malignant disease of hematopoietic tissue. $\mathrm{T}(15,17)$ chromosome rearrangements lead to this malignant tumor. APL is characterized by representative promyelocytic leukemia protein/retinoic acid receptor a gene fusion and high invasiveness and infiltration in clinical practice [32-35]. The oncogenic protein produced by the fusion can antagonize myeloid differentiation and promote APL to initiate cell self-renewal, leading to abnormal development of promyelocytic bone marrow infiltration [36, 37]. Owing to high early mortality, high recurrence rate, low survival 


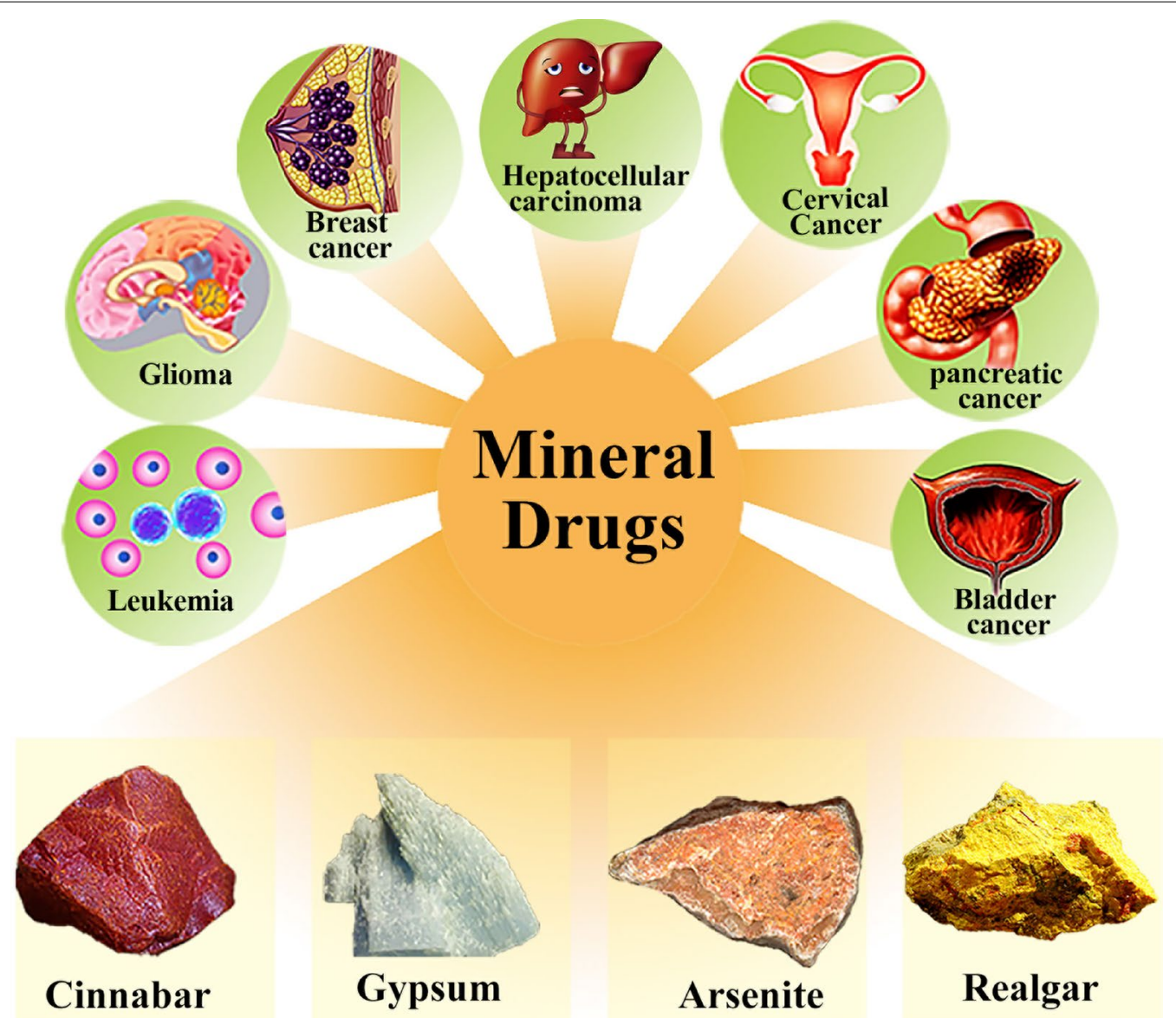

Fig. 3 Schematic illustration showing the pharmacological activity of mineral drugs and their advantages in tumor treatment. (The copyright of the pictures from network sources in the figure is shown below. Copyright ${ }^{\oplus} 2021$ Sohu All Rights Reserved. Copyright ${ }^{\circledR} 1997-2021$ https://www.163. $\mathrm{com} /$.

rate, and coagulopathy. It was once considered to be the most rapidly fatal leukemia [32]. Although all-trans retinoic acid (ATRA) and anthraquinone chemotherapy are recognized as effective therapies for APL, their side effects such as cardiotoxicity cannot be ignored [38]. Therefore, scientists are always devoted to finding ways to validly remedy APL. In the past 60 years, significant progress has been made in the treatment of APL. The introduction of ATO holds promise for the treatment of APL.

Arsenic has always been regarded as the king of poisons. However, its active ingredient ATO has recently been considered as one of the most effective drugs for the treatment of APL. As early as the 19th and early twentieth centuries, Western doctors found that arsenic had special effects in the treatment of leukemia, and adopted a variety of treatment methods such as oral, rectal, intramuscular and intravenous administration. Arsenic trioxide has been widely used in the world since the 1990s to treat acute promyelocytic leukemia. It is an original invention of Chinese and Western medicine experts from Harbin Medical University in China. The use of hemoglobin can show extraordinary binding force with exogenous drugs, so that trivalent arsenic can be combined with hemoglobin. In addition, tumor cells will absorb nutrients preferentially to normal cells in the tissue, so that trivalent arsenic is mainly absorbed by tumor cells. destroy tumor cells. In addition, hemoglobin has the advantages of low cost, complete biocompatibility, and easy genetic engineering, all of which make hemoglobin an ideal drug delivery material. Fan et al. designed nanoparticles composed of polyethylene glycol (PEG), retinoic acid (RA), and 2-chloro-1,3,2-dioxaarsolane (PEG-AsRA), which exhibited superior water solubility, stability, and biocompatibility [39]. Zhang et al. developed an ATO multifunctional drug delivery system based on a $\mathrm{pH}$-low insertion peptide modification, which is termed as $\mathrm{MnAs@SiO}$-pHLIP (Fig. 4A). Figure 4B, C, F illustrate that arsenical and manganese ions can aggregate efficiently in cancer cells. This drug delivery system can 


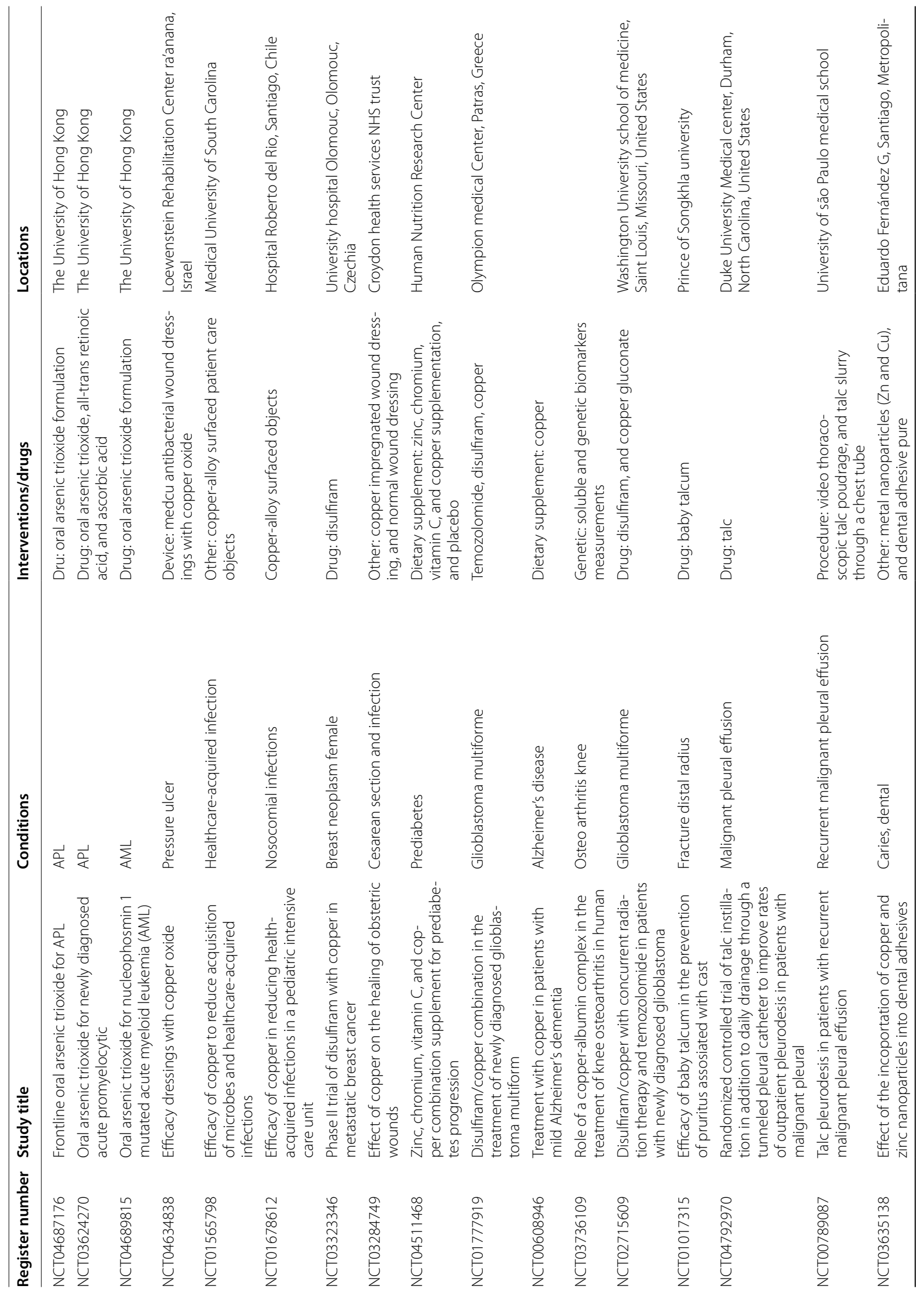



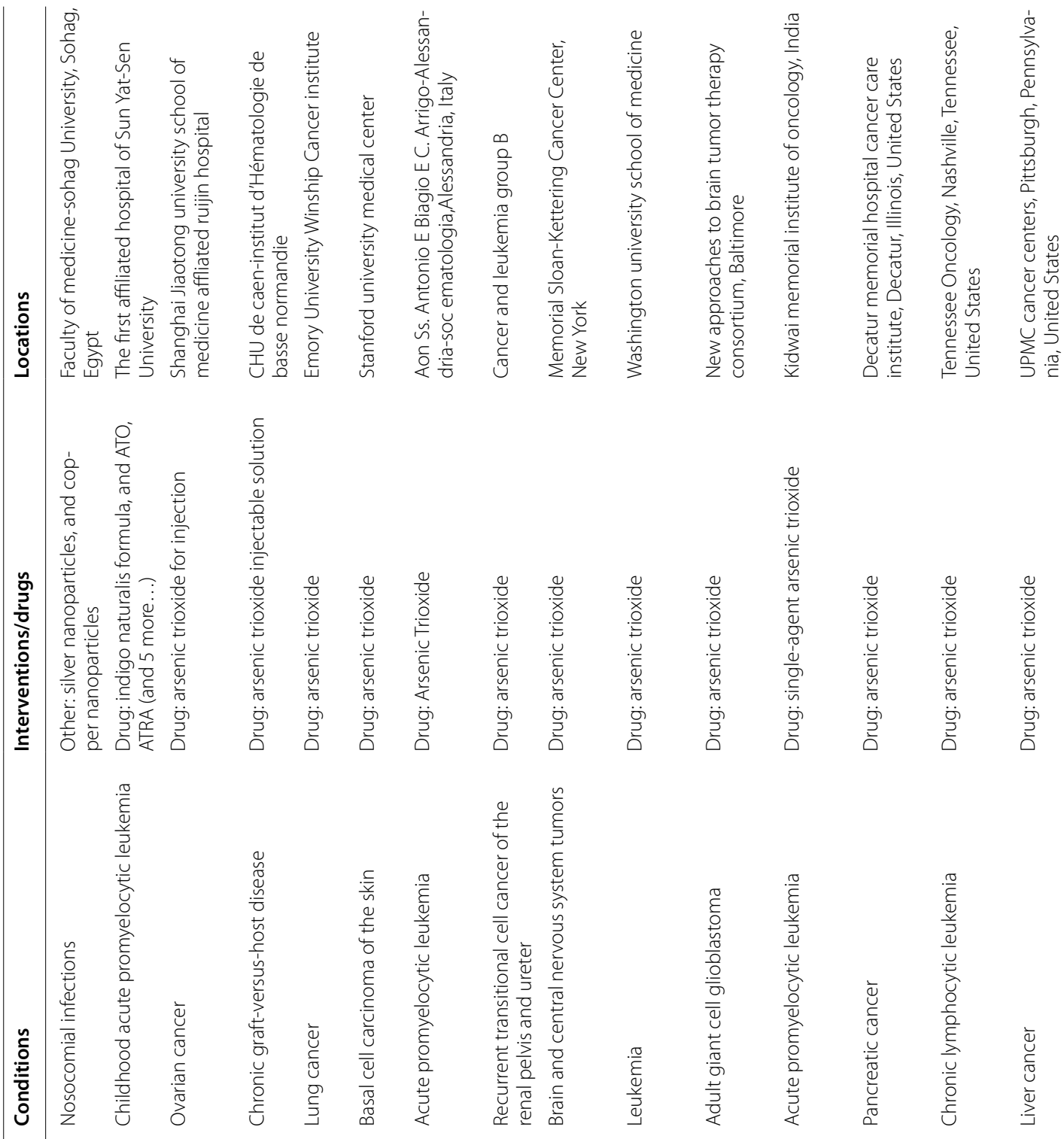

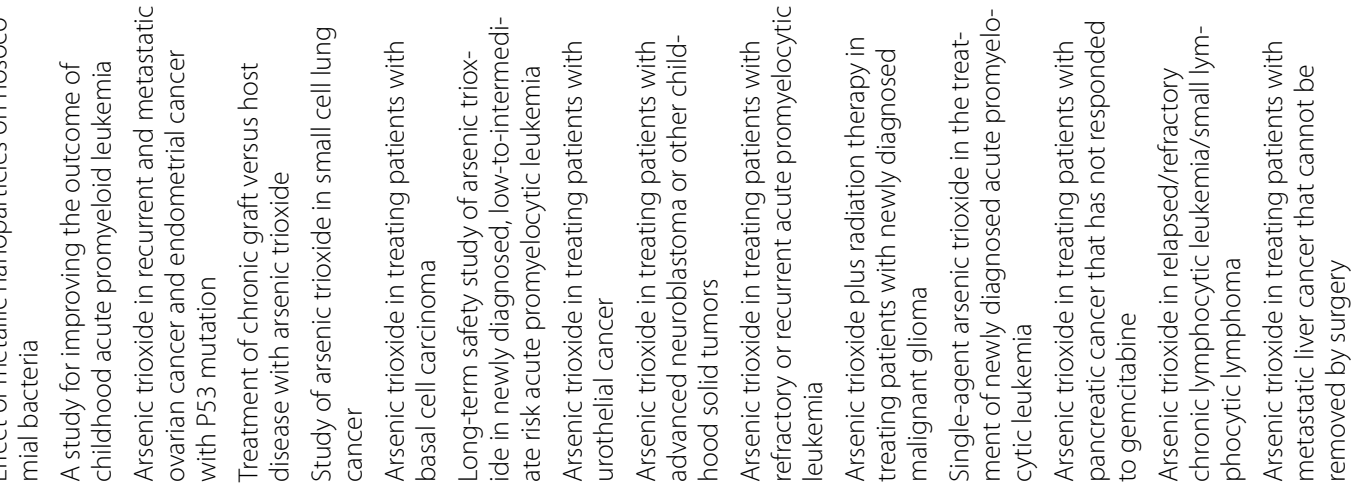




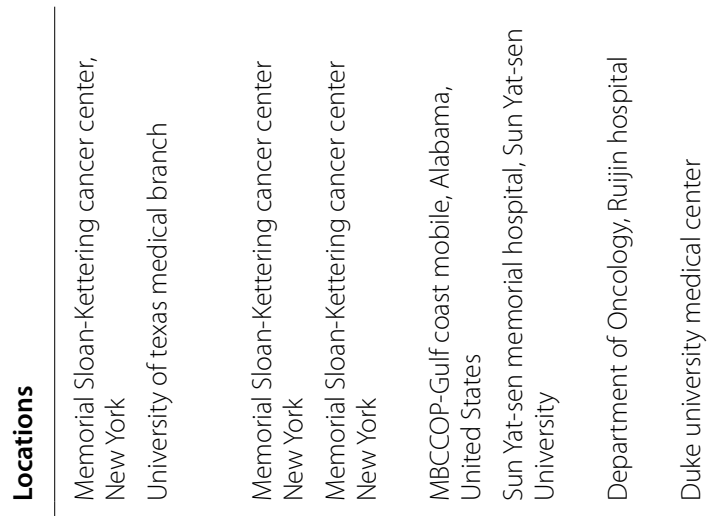

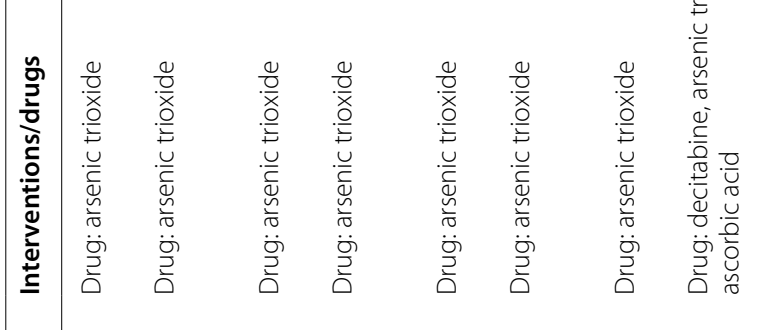

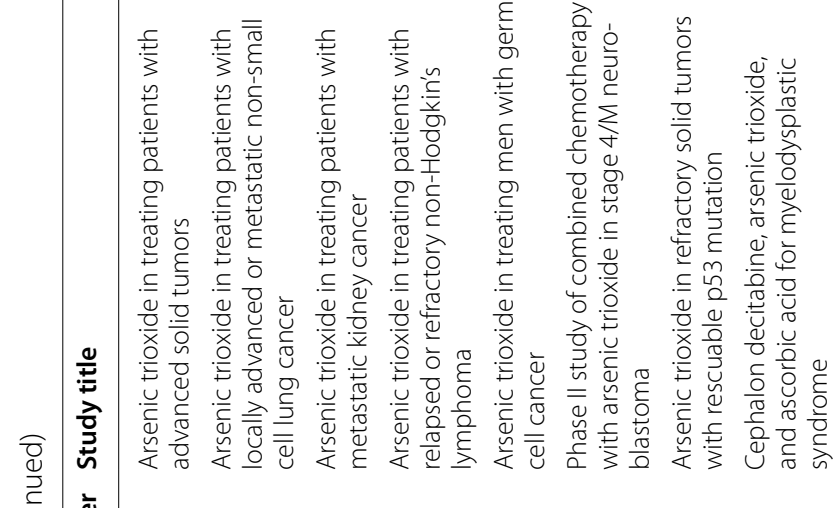

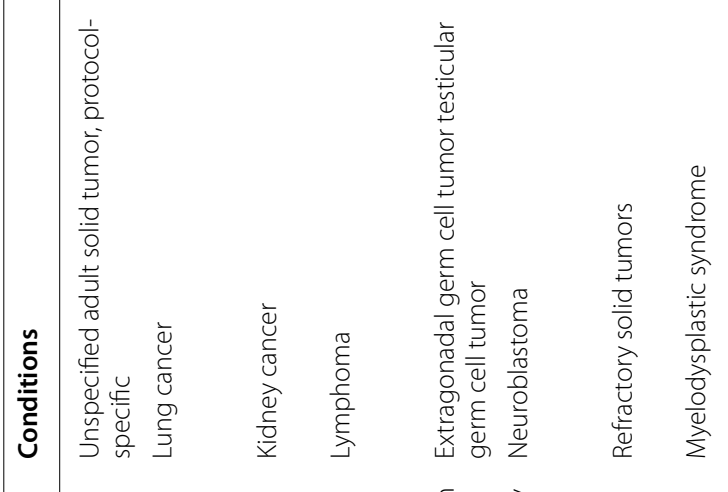

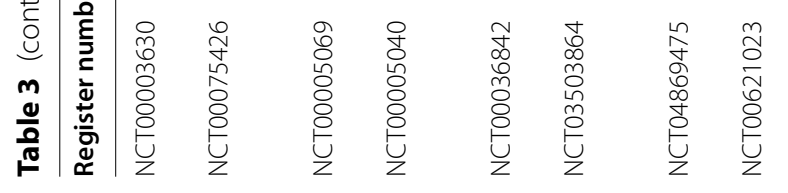



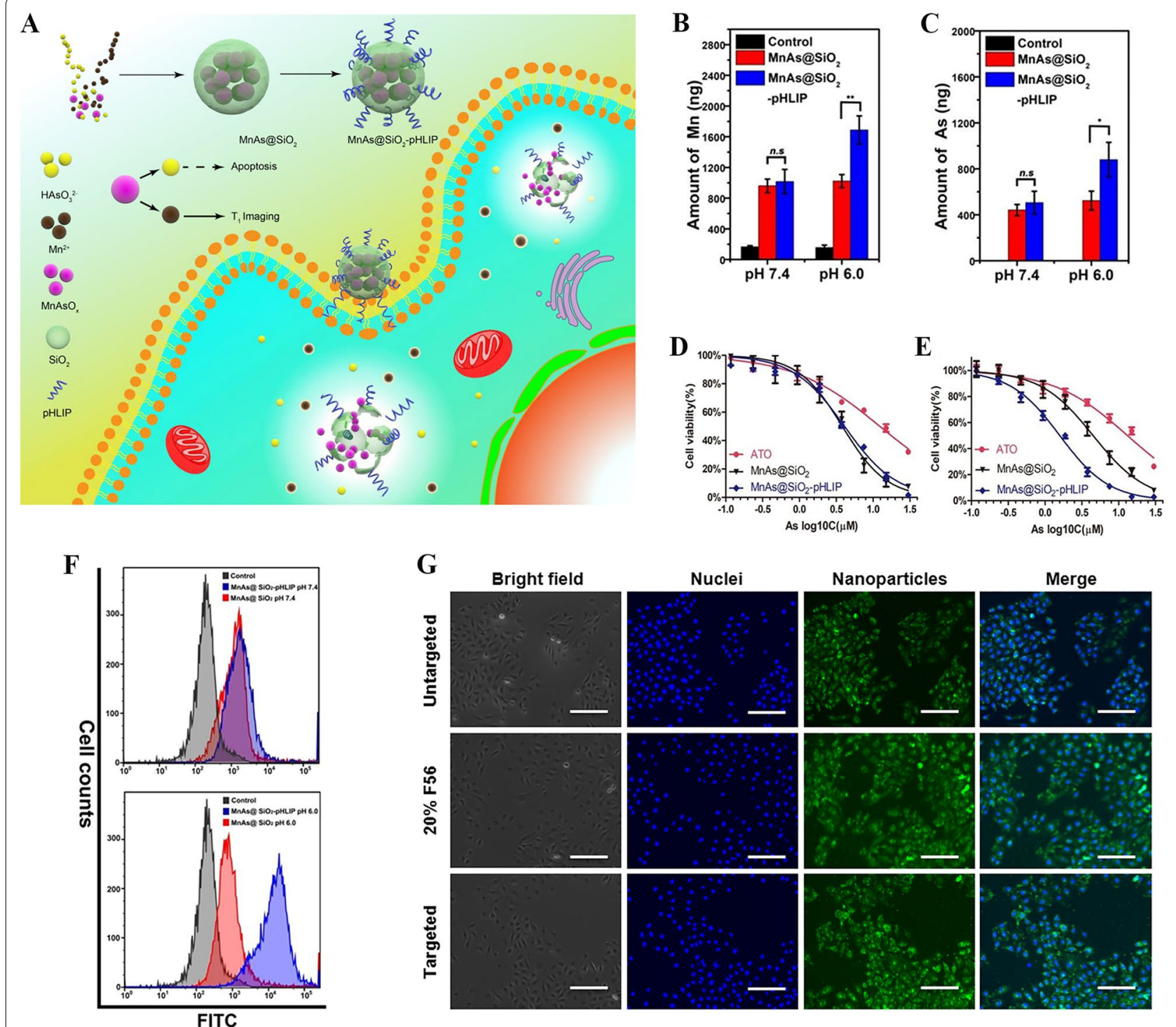

Fig. 4 A Schematic illustration of the synthesis of MnAs@SiO2-pHLIPs and their functions in the tumor. After treating SMMC-7721 cancer cells with

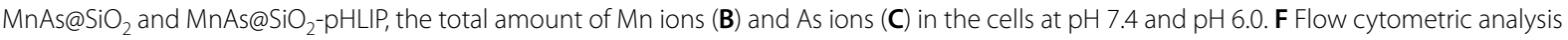
of SMMC-7721 cells incubated with different drugs for $2 \mathrm{~h}$ at different pH. SMMC-7721 cells served with free ATO, MnAs @ SiO ${ }_{2}$, and MnAs @ SiO 2 pHLIP at pH 7.4. D And the cell viability at pH 6.0 (E) and pH 7.4. $(n=6)$ [40] Copyright 2019, Royal Society of Chemistry. G Fluorescence microscopy images of prepared oligopeptide nanoparticles in HUVEC cells (scale bar:200 $\mu$ M). [41] Copyright 2020, Elsevier

controllably release loaded ATO in response to an acidic environment, thereby promoting the apoptosis of cancer cells in Fig. 4D, E [40]. The application of protein peptides provides an efficient platform for the delivery of ATO. Fan et al. showed that double oligopeptide nanoparticles based on the principle of reverse micelles can significantly increase the loading rate and stability of ATO (Fig. 4G). This bone marrow targeted drug delivery strategy may be utilized to treat chronic myeloid leukemia and other hematological malignancies originating from bone marrow [41]. Zn-based metal-organic framework zeolitic imidazolate framework- 8 has proved to be a suitable candidate material for transporting arsenic compounds, which could not only enhance the transportation of ATO but also possess $\mathrm{pH}$-responsive release capability [1]. Otherwise, Jin et al. loaded arsenite into liposomes (LIP) by electrostatic interaction with manganese ion to construct liposome-encapsulated arsenic manganese complex (LIP@MnAs $)_{x}$ ). The research results show that LIP@MnAs ${ }_{x}$ is a desired arsenic-based nano-drug 
system, which can improve the non-specific distribution of $\mathrm{NaAsO}_{2}$ in the body [2]. These all provide us with ideas for delivering ATO to treat APL.

\section{Glioma}

Glioma is the most common primary intracranial disease with invasiveness growth, poor prognosis, high recurrence rate, and high mortality [42]. Multi-mode therapy such as chemotherapy, radiotherapy, and surgical resection are the main choices for the treatment of gliomas $[43,44]$. However, the emergence of drug resistance and the presence of blood-brain barriers (BBB) continue to be problems impeding the mission of drugs. At the same time, the application of drug chemotherapy often generates irreversible damage to the body, and patients are usually accompanied by severe adverse reactions and pain. In addition, after brain surgery to remove tumor tissue, the residual tissue still has a trend of growth and invasion, resulting in a high recurrence rate [45].
Therefore, it is crucial to exploit new drugs and modus for the treatment of gliomas.

It is well known that arsenic and its compounds are highly toxic, especially trivalent arsenic and pentavalent arsenic. Further studies have shown that ATO has an inhibitory effect on intractable diseases, including gliomas. The anti-cancer mechanisms of ATO include regulating apoptosis and autophagy, promoting the production of intracellular reactive oxygen species, and inhibiting tumor stem cells [46, 47]. Unfortunately, there are still many problems in ATO therapy, such as severe adverse reactions, high organ clearance, and poor bloodbrain barrier permeability. Therefore, the design of drug carriers to overcome the BBB has become the focus of research. Tao et al. grafted polyacrylic acid (PAA) onto mesoporous silica nanoparticles (MSN) and combined them with angiopep-2-liposomes to prepare nanocarrier (ANG-LIP-PAA-MSN) (Fig. 5A) [48]. Figure 5B shows that modified agents are better absorbed by cells.

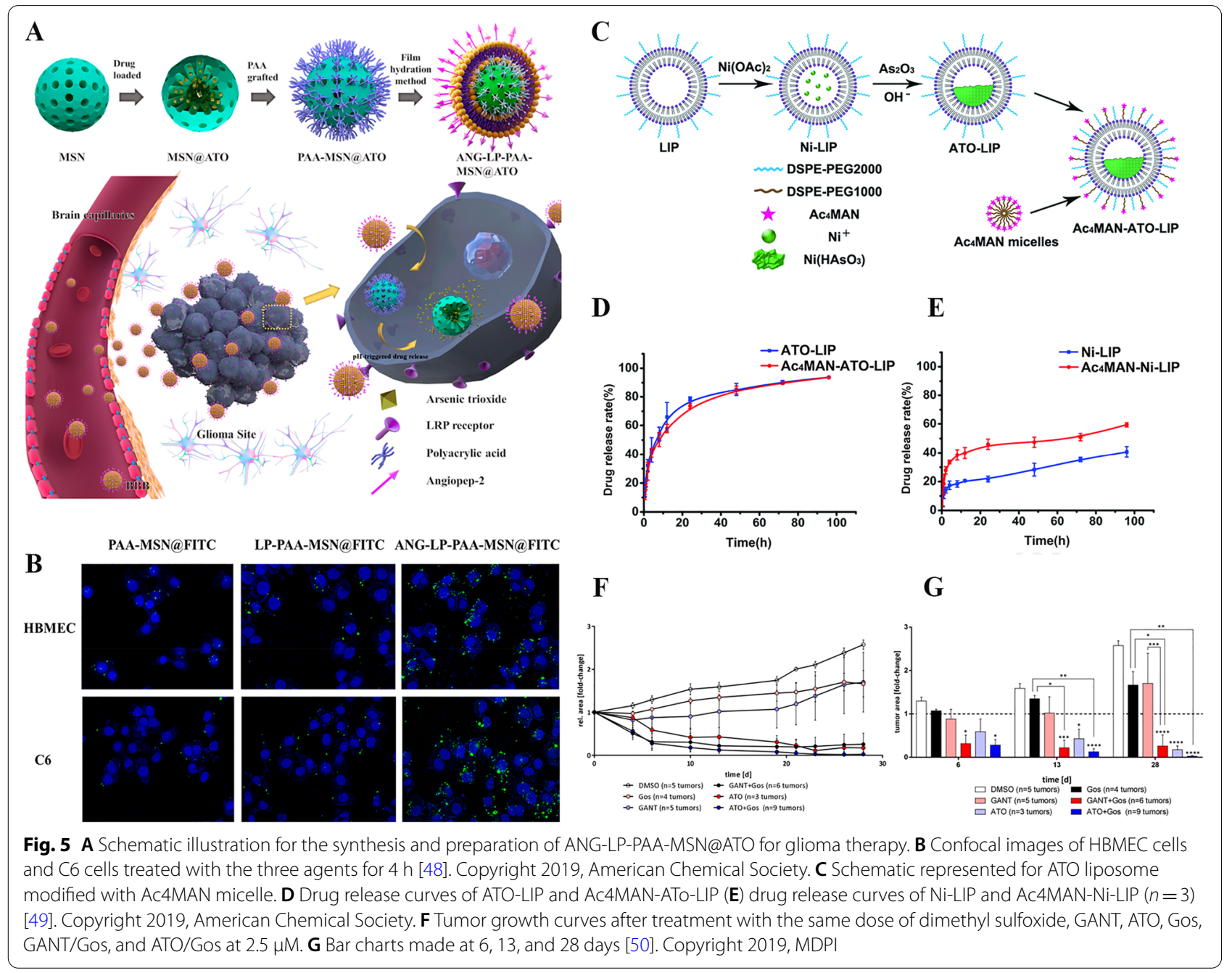


Otherwise, Wang et al. showed that mannose (MAN) substrates without acetyl groups can promote the entry of vesicles into the brain, while the surface of LIP undergoes deacetylation of the Ac4MAN group under the action of enzymes, which is the "prodrug-like" characteristic of vesicles. Therefore, they insert distearoyl phospho-ethanolamine-polyethylene into the liposomes, thereby developing the "prodrug-like" ATO liposomes called Ac4MAN-ATO-LIP (Fig. 5C) [49]. Figure 5D, E show that liposomes modified with surfactants have a better drug release rate. To strongly suppress tumor growth or even tumor removal, Linder et al. designed a combination therapy consisting of the hedgehog signaling pathway inhibitors GANT61, anticancer drug gossypol (Gos), and ATO in Fig. 5F, G [50]. These provide a promising targeted therapy for the treatment of glioma.

In addition, modifying groups on drug carriers can enhance the targeting ability by recognition and combination of the $\mathrm{BBB}$, including angiopep-2 (ANG) and TGN peptides $[48,51,52]$. With the help of these groups, drugs are commendably accumulated in the tumor tissue area and play a role in targeted therapy. Other tumor-targeted modified peptides also ulteriorly enhance the penetration of the preparation, such as the internalizing RGD (iRGD, CRGDK/RGPD/EC) peptides. IRGD peptides can bind to the neuropilin-1 receptor of tumor cells, thus reducing cellular internalization. This suggests that we can design dual targeting nanomedicines to the blood-brain barrier and tumor. And using different nano-drug platform strategies according to different diseases is the trend of nanomedicine development in the future.

\section{Hepatocellular carcinoma}

The most popular pernicious tumor in the world is must belong to hepatocellular carcinoma, which is ranked the third one in cancer death. In the past decades, the hepatitis $B$ virus (HBV) has been confirmed to be the main pathogenic factor. About $50-80 \%$ of liver cancer cases in the world are caused by HBV infection [53, 54]. Studies have shown that HBV infection can directly or indirectly lead to HCC through coinfection with hepatitis $C$ virus, heavy drinking, or type 2 diabetes. The main mechanisms include $\mathrm{HBV}$ gene amalgamation, genomic uncertainty induced by variant, and activation of tumor signal pathway [55]. As the result of intense malignant and occultation of hepatocellular carcinoma, many patients with liver cancer have unsatisfactory surgical results, and the recurrence rate and mortality are high. Furthermore, HCC has high drug resistance in conventional chemotherapy and radiotherapy [56]. Therefore, it is a great challenge to develop therapeutic methods that can improve the efficacy and decrease the toxicity of HCC. ATO is a mineral drug with a positive curative effect on a variety of tumors. It has the characteristics of multitarget and multi-efficacy of TCM and has been proved to have a positive effect on multifarious tumors. Nadra et al. studied the irradiation of normal liver and hepatoma cells (Hep3B) at 24,48, and $72 \mathrm{~h}$ with different consistencies of ATO [57]. And the results show that ATO is promising to be a predominant drug for the curing of $\mathrm{HCC}$.

However, on account of the systemic toxicity, swift renal elimination, and greater serum protein binding rate of ATO [58], ATO is seriously limited in the treatment of HCC [59]. We know that reducing the size of nanoparticles and preparing smaller ATO nanoparticles can improve the ability of nanoparticles to penetrate $\mathrm{BBB}$ and cell membranes. ATO microcrystalline microspheres with very high-density cores were prepared by embedding ATO microcrystalline with polylactide glycolic acid. ATO micro-crystal microspheres can continuously induce the production of reactive oxygen species and apoptosis of liver carcinoma cells. And reduce tumor growth by $80 \%$ through local administration. It realizes local management of ATO, avoids systemic exposure, and possesses higher pharmacological stress [60]. In recent years, chemotherapy combined with phototherapy and hyperthermia has obvious advantages in tumor treatment. Wu et al. developed a mitochondria-targeted carrier with local precisely controlled release of ATO by loading ATO into the cavities of nano zirconia microspheres [61]. After the ATO nano-drug was delivered to the tumor site through the enhanced permeability and retention effect, the tetradecyl alcohol was used as a phase change material (PCM) in vitro to be exposed to triphenylphosphine (TPP) by microwave control in vitro phosphine targets the ligand to enhance the mitochondrial killing effect of ATO. A kind of mitochondrial-targeted ATO controlled release carrier (TPP-PCM-ATO@ $\mathrm{ZrO}_{2}$ ) was constructed by coupling microwave-sensitive smart switches and mitochondrial targeting molecules outside the microspheres (Fig. 6A). The developed drug delivery system has (1) strong permeability and can inhibit tumor cell proliferation and promote apoptosis Fig. 6C-E, (2) controlled release of ATO in tumors, (3) ligands that can point mitochondria in Fig. 6B, (4) microwave therapy via an extracorporeal approach for improved efficacy. However, the mechanism of ATO mingled with microwave hyperthermia needs further study. Chitosan is a natural polysaccharide. Because of its good biocompatibility, biodegradability, and cytotoxicity to cancer cells, chitosan has become an ideal material for tumor treatment [62]. It is reported that by encapsulated ATO in PEG and lactic acid-modified chitosan (PLC). A nano-drug targeting ATO release from liver cancer cells was then prepared by coating with poly (lactide-co-glycolide) (PLGA) nanoparticles $\left(\mathrm{As}_{2} \mathrm{O}_{3}\right.$-PLGA/PLC NPs) 

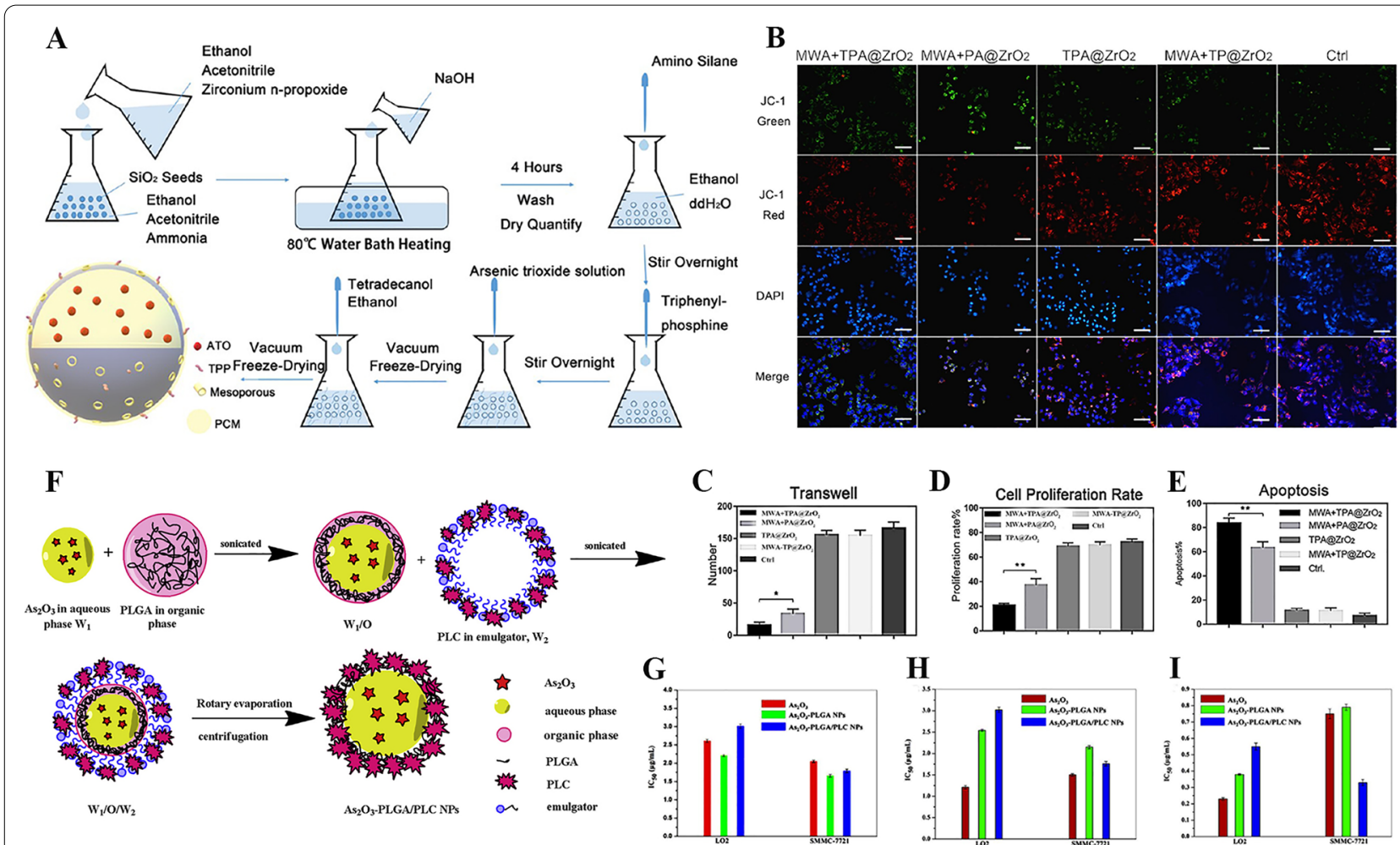

Fig. 6 A Construction of the composite nanodrug delivery system. B JC-1 mitochondrial membrane potential staining (200x). Cell migration (C), proliferation (D), and apoptosis (E) test results after treatment with the composite nanoparticles [61]. Copyright 2020, American Chemical Society. F The synthesis scheme of $\mathrm{As}_{2} \mathrm{O}_{3}$-PLGA/PLC NPs. IC50 values of the nanoparticles against LO2 and SMMC-7721 cells after 24 (G), 48 (H), and 72 (I) $\mathrm{h}$ incubation (mean $\pm S D, n=5$ ) [3]. Copyright 2019, Elsevier

(Fig. 6F). The prepared nano-drugs have good targeting to hepatocellular carcinoma and can effectively release ATO to cancer cells. Experimental studies showed that $\mathrm{As}_{2} \mathrm{O}_{3}$ PLGA/PLC NPs had an obvious inhibitory influence on human hepatoma cell lines SMMC-7721, but had low cytotoxicity on normal human hepatocytes (LO2 cells) in Fig. 6G-I [3]. Therefore, PLGA/PLC nanoparticles are a safe and effective drug carrier for liver cancer chemotherapy. Recent research reported the development of magnetic targeted nano-carrier technology has brought a new research direction for the effective transportation and release of ATO. Approach by modifying ATO prodrugs $\left(\mathrm{NiAsO}_{\mathrm{x}}\right)$ loaded magnetic large-pore mesoporous silica nanoparticles (M-LPMSNs) with folic acid (FA), the responsiveness was prepared to released nano drugs (M-LPMSN-NiAsO ${ }_{x}$-FA). Further experiments show that the prepared nanomedicine has stronger cytotoxicity and the ability to promote cell apoptosis than the traditional free ATO [63]. ATO-containing magnetic silica nanoparticles can not only effectively resist hepatocellular carcinoma, but also have the ability to detect tumors in real-time. It has great application prospects and advantages in HCC treatment.

\section{Cervical carcinoma}

Cervical cancer is a common malignant tumor of the female reproductive system with a high incidence [64]. There are 500,000 new cases annually in the world. Comprehensive treatment including surgery is the main principle of treatment in the clinic. However, the cure rate of postoperative recurrence is less than $20 \%$, in addition, chemotherapeutic drugs lack targeting and there are many side effects [65]. As there is no breakthrough in the comprehensive treatment of advanced cervical cancer, insights into the traditional mineral drug of ATO may be an alternative manner in cervical cancer treatment.

ATO has been proved to be effective in many cancers including cervical cancer. However, there is a lack of experiments to verify the anti-cervical cancer mechanism. Nowadays, Zhang et al. preliminary predict that ATO can induce reactive oxygen production to promote cell apoptosis by methyl thiazolyl tetrazolium (MTT) and flow cytometry. Western blotting and flow cytometry indicated that ATO suppresses hypoxia-inducible factor- $1 \alpha$ expression, which aimed to effectively inhibit the proliferation and invasion of Siha cells and promote apoptosis [65]. ATO due to the dose-limited toxicity 
and poor pharmacokinetics in clinical trials requires the right vehicle to be carried [66]. The liposome is a common drug delivery carrier to encapsulate ATO in cervical cancer treatment. Liposomal ATO has been proved to exert better efficacy and lower cytotoxicity. At the same time, liposomes are regarded as a reservoir of drugs, and the slow release of drugs can avoid the toxic and side effects of high concentrations of ATO. Wang et al. showed that compared with free ATO, liposomal ATO further reduced the level of human papillomavirus-E6 protein and induced apoptosis of HeLa cells [67]. In addition, the concentration of arsenic in cells was measured by an inductively coupled plasma optical emission spectrometer (ICP-OES). Results showed that the intracellular concentration of ATO transported by liposomes was 3 times lower than that of free ATO, which verified the slow accumulation of ATO and lower cytotoxicity. The liposomes with different particle sizes and charges also have an impact on efficacy. Therefore, Akhtar utilized ICP-OES for the quantitative analysis of arsenic. Figure $7 \mathrm{G}, \mathrm{H}$ show that neutral liposomes of $100 \mathrm{~nm}$ were the highest drug loading rate, which was $24.2 \% \mathrm{As} / \mathrm{P}$ $( \pm 0.848)$ [64]. In addition, the cytotoxicity test showed that neutral liposomes were the least toxic.

\section{Other nano-preparations}

The development of biomimetic nanoparticles and targeted drug delivery technology has opened up a new research path for mineral drugs. And the components of traditional Chinese medicine and mineral drugs are gradually attracting attention in the drug delivery system. For example, antigen and antibody recognition has high specificity and affinity, which is a very ideal targeted drug delivery carrier. CD44v6 is a membrane antigen overexpressed in epithelial tumors such as pancreatic cancer, hepatocellular carcinoma, and breast cancer. The anti-CD44v6 single-chain variable fragment (scFv (CD44v6)) screened from the human phage antibody library was assembled into vesicles with an amphiphilic copolymer. Arsenite ions (As) were encapsulated in the core of vesicles to prepare vesicle nanoparticles (scFv-As-NPs). Experiments showed that the prepared

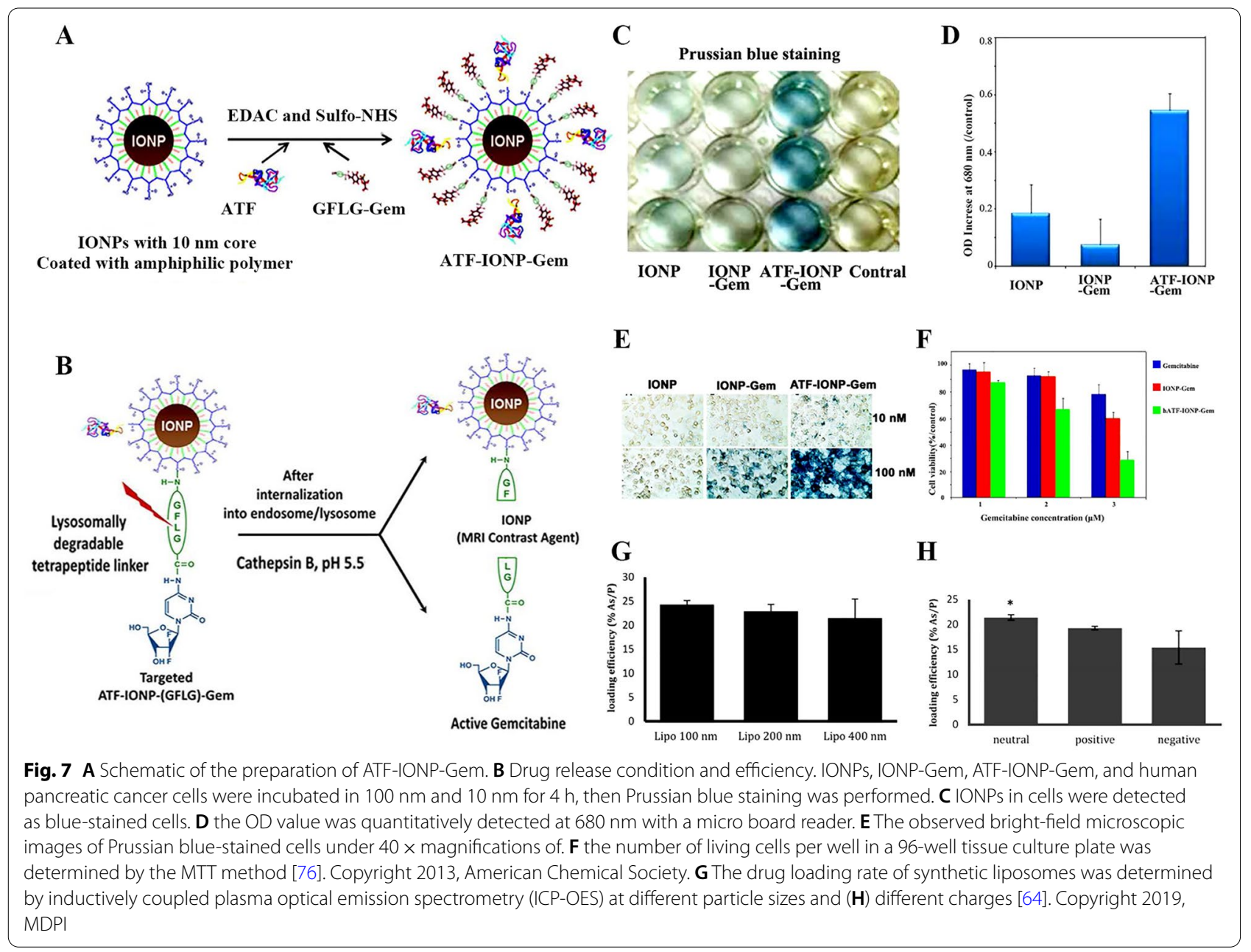




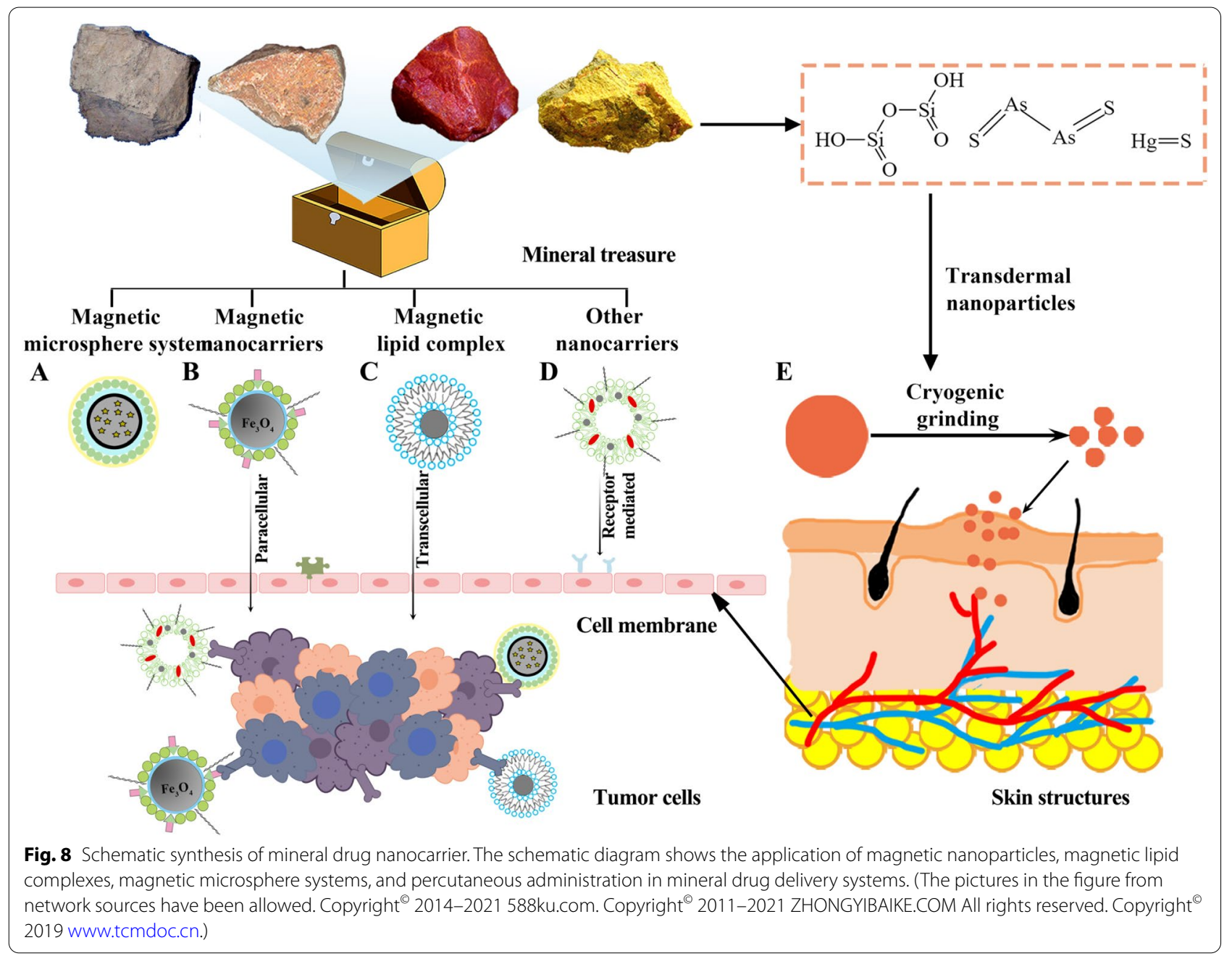

arsenic nanovesicles had a better effect of inhibiting tumor growth and promoting tumor cell apoptosis, providing an efficient and safe platform for the delivery of mineral drug arsenic [68]. (-)-Epigallocatechin-3-gallate (EGCG) is a phenolic compound with rich content of tea polyphenols and good anti-tumor activity. Recent studies have shown that the combination of EGCG and metal ions can significantly improve drug activity and reduce metal toxicity, more importantly, it is also a good nanodrug carrier $[69,70]$. Wei et al. combined the realgar with EGCG and prepared the nano-drug (EGCG-RNPs) by coprecipitation method. It was proved that EGCG as a carrier could significantly increase the uptake of HL-60 cells to realgar, which provided a new treatment for APL. In recent years, the great advantage of protein biomineralization to synthesize nanoparticles to enhance the synergistic effect of drugs has been reported in the literature. Macrophage membrane has good biocompatibility and can be used as a carrier for biomimetic nano preparations. During the treatment of atherosclerosis, Huang et al. [71] used macrophage membranes to wrap $\mathrm{Fe}_{3} \mathrm{O}_{4}$ to prepare liposome $\mathrm{Fe}_{3} \mathrm{O}_{4} @ \mathrm{M}$ nano-drugs, which can be used for magnetic resonance targeted detection, which can better detect and treat the early stage of the disease stage. Bovine serum protein is also a common biomimetic nanomaterial. $\mathrm{FeS}_{2}$ nanoparticles synthesized by protein biomineralization have synergistic tumor therapeutic effects in vivo and in vitro photothermal photodynamic therapy and have no significant toxicity [72]. All these have proved that compared with traditional preparations (pills, powders, decoctions, etc.), modern pharmaceutical preparations can give full play to the characteristics of low-dose, low-toxicity, targeted transportation, and better play the role of mineral medicine effect.

\section{Carrier function of mineral medicine in disease diagnosis and treatment \\ Magnetic nanoparticles}

With the growing trend of drug delivery system research, nanotechnology has become the focus of 
modern research owing to its target ability, longer circulation in vivo, and fewer side effects [73]. Among them, magnetic nanoparticles have many effects in cancer treatment for their good biocompatibility, quick magnetic response, and excellent fluorescence imaging. And it exhibits good application prospects in magnetic resonance imaging (MRI), magnetic fluid hyperthermia (MFH), and magnetic drug targeting (MDT) therapy. MRI is based on the fact that magnetic nanoparticles are coupled with fluorescent agents for clinical optical diagnosis. The report has shown that tumors can form damage or deactivation when the temperature reaches or exceeds $43{ }^{\circ} \mathrm{C}$. Therefore, the principle of MFH is to apply high temperatures to kill cancer cells [74]. As shown in Fig. 8B, magnetic nanoparticles (MNPs) can utilize a magnetic field to generate heat to achieve the purpose of thermotherapy for their excellent magnetism. However, it may also cause damage to normal and healthy cells probably owing to the lack of selectivity of hyperthermia. Drug targeting is the key to specific therapy, and magnetic nanoparticles can effectively accumulate in the target tissue and site when magnetic fields take effect. In addition, MNPs can also exert active targeting through selective through its targeting ligands binding to tumor over-expressed receptors [75]. When MRI, MFH, and MDT combine, showing effective diagnosis and treatment.

The general preparation methods of MNPs include coprecipitation and organic thermal decomposition. The coprecipitation method is prone to nano-agglomeration. Therefore, the precipitation hydrolytic alkali method, has relatively good stability and dispersion without high boiling point solvent and high temperature, suggesting a good substitute [76]. In magnetic nanoparticles, drugs can be coupled through covalent or non-covalent pathways. Non-covalent coupling refers to physical adsorption and entrapment, while covalent binding refers to the formation of covalent chemical bonds between MNPs and drug molecules. Covalent binding between drug loading and release is more difficult than non-covalent binding. Moreover, the residual catalyst in the binding process is also toxic to the physiological environment. When MNPs reach the designated site, it is released under-stimulation, including chemical and biochemical stimuli and external magnetic, light, and thermal stimuli.

Nanoparticles have always shown excellent efficacy in the treatment of cancer. However, there are some problems to be further studied, such as less targeted accumulation in vivo, short cycle time, ease to be eviscerated, and so on. Therefore, optimizing the physicochemical properties and modifying the surface of nanoparticles has become the focus of follow-up research [77]. The report showed that the target ligand, an amino-terminal fragment (ATF) peptide, binds to the urokinase plasminogen activator receptor. Targeted delivery of the hydrophilic drug gemcitabine (Gem) by coupling with magnetic iron oxide nanoparticles (IONPs) (Fig. 7A, B). Figure $7 \mathrm{C}, \mathrm{D}$ showed that cell uptake was significantly increased in the ATF-IONP-Gem group after Prussian blue staining, about three times as much as in the nontargeted group. Figure 7E shows that in the IONPs-Gem group without ATF modification, the cell uptake of cancer cells was still quite low even at high concentrations, indicating that the modification of ATF enhanced the targeted therapy of drugs. In addition, Fig. 7F shows that the cytotoxicity experiment showed that the ATF-IONPGem group had a better level of cell survival than other groups, demonstrating that it reduced the cytotoxicity [78]. Folic acid-modified magnetic iron oxide bovine serum albumin (BSA) nanoparticles were also designed. At the same time, doxorubicin (DOX) was loaded to achieve the purpose of targeted therapy, and the key to targeted therapy was folate receptor overexpression cells in tumors [79]. Through the observation of transplanted tumor tissue sections, the results showed that the FADOX-BSA MNP hyperthermia group showed significant differences from MFH and MDT groups in an inflammatory response and cell necrosis. This indicates that targeting ligand coupling magnetic nanoparticles possess good antineoplastic activity. In addition, Lee et al. utilized silica magnetic nanoparticles to load drugs. Silica-mediated nanoparticles have stable chemical properties, low cytotoxicity, and large pore volume, which can provide a better platform to carry drugs and imaging agents [80].

\section{Magnetic lipid complex}

As an endogenous nano-carrier, liposome is composed of three major biological components: phospholipid bilayer, transmembrane proteins, and internal core. Liposomes have the following advantages: (1) high biocompatibility and low toxicity, (2) the ability to carry both water-soluble and water-insoluble drugs, (3) the highly modifiable surface, (4) the controllable size. MNPs exert multi-mode therapy in clinical treatment and become the focus of modern diagnosis and treatment [2]. Liposome and magnetic nanoparticles are utilized to be shell and core, respectively. This core-shell structure, also known as lipid magnetic nanoparticles (MLs), can effectively maintain the colloid stability of nanoparticles and prevent drug leakage (Fig. 8C). In the bilayer membrane of liposomes, the inner membrane is firmly adsorbed on the magnetic nanocomposites. While the outer membrane is relatively loose and easy to functionalize. For example, polyethylene glycol is utilized to perpetuate the cycling time in vivo. Otherwise, the modification of targeted ligands and fluorescent agents is to achieve drug 
targeting and bimodal imaging, respectively. Choi et al. reported that magnetic liposomes showed a strong anticancer effect and tumor targeting on colorectal cancer cells of CT26 mice under the action of an external magnetic realm [81]. Ketkar et al. achieved high hepatocyte targeting by designing lactose functionalized magnetic liposomes [82]. Soenen et al. reported that MLs can perform simultaneous MRI and fluorescence imaging because of the particularity of the bilayer of liposomes $[83,84]$. Therefore, the organic combination of liposomes and magnetic nanoparticles is the optimization of a single delivery carrier among them. In addition, the research began to pay attention to some new types of liposomes, which not only have the advantages of liposomes but also have their unique properties. For example, $\mathrm{pH}$-sensitive liposomes can be selectively released in weakly acidic tumor anaerobic areas [85].

\section{Magnetic microsphere system}

Microsphere refers to the dispersion system formed by drug dispersion in natural polymers and matrix polymers. Natural polymers comprise starch, albumin, and gel [86]. The matrix polymers of microspheres include polylactic acid, polylactic acid glycolic acid, and chitosan. Among them, PLGA has become the first choice of drug carriers for its high stability and entrapment efficiency [87]. Therefore, the microspheres show good biocompatibility, biodegradability, and sustained release. However, the clinical study indicates that restrictions of microsphere preparation have remained, such as low drug loading, low targeting, and poor stability [88].

Now, most studies have focused on strategies to improve drug loading and release. These strategies can be divided into four groups: (1) optimization of polymers: low molecular weight and hydrophobicity, (2) regulation of the external water phase $\mathrm{PH},(3)$ increased polymer concentration, (4) emulsifier addition. Otherwise, Fig. 8A illustrates the application of magnetic nanoparticles (MNPs) to encapsulated microspheres is also gradually emerging. MNPs have excellent magnetic targeting and colloidal stability. Thus, the combination of magnetic nanoparticles and microspheres can play their respective advantages. And that provides a new direction for the clinical treatment of nanometer micro balloons. Srinivasan Ayyanaar and other researchers designed an associated system composed of iron oxide nanoparticles and poly (D,L-lactide-co-glycolic acid) to load curcumin [89]. MTT and cell colony formation experiments showed that the designed nano-system exhibited satisfactory cytotoxicity to cancer cells and could effectively inhibit cell colony-forming. Moreover, the morphological characterization experiments showed that the system also had good stability. In addition, the drug liberates tentative showed that the drug was targeted released in cancer cells under the action of the magnetic field. These experimental results show that the microspheres encapsulated by magnetic nanoparticles can better solve the problem of single microsphere preparation.

\section{Other nanocarriers}

Except for microspheres and liposomes, $\mathrm{Fe}_{3} \mathrm{O}_{4}$ NPs can also be designed as other preparations, including gels, vaccines, and aerosols. Nahid and other researchers designed multi-stimulus-responsive magnetic nanohydrogels (MNHGs) to load doxorubicin hydrochloride [90]. The results of anti-cervical cancer experiments demonstrated that compared with single magnetic nanoparticles, MNHGs showed higher drug loading rate and cytotoxicity. In addition, owing to their superior $\mathrm{pH}$, magnetic field, and thermal response, MNHGs show splendid targeting ability. Yi Zhao et al. focused on the potential of iron oxide nanoparticles to be adjuvants for cancer vaccines. In this research $\mathrm{Fe}_{3} \mathrm{O}_{4}$ NPs not only work as an antigen presentation system but also as immune enhancers for antigens. The results of immune response and anti-colon tumor experiments showed that the preparation induced a stronger immune response and improved the anti-tumor effect [91, 92]. Of note, $\mathrm{Fe}_{3} \mathrm{O}_{4}$ NPs owing to their superior magnetic targeting provide a new idea for the aerosol treatment of bronchogenic carcinoma. Mehdi Mohammadi et al. verified the targeted therapeutic effect of magnetic aerosol drug targeting through the Weibel symmetrical tree lung model [93].

Halloysite is a submicron hollow cylindrical aluminosilicate clay. Halloysite is a natural carrier with good biocompatibility and sustained-release properties, which can be used to transport a variety of drugs (Fig. 8D) [94-97]. Viviana et al. designed halloysite nanotubes to transport resveratrol. The system has shown an ideal encapsulation effect and an excellent ability to release the drug slowly, thus improving the efficacy of tumor therapy [98]. A novel co-delivery method of polysulfone mucopolysaccharides embedded in amine-functionalized halloysite nanotubes is reported in this paper. For this reason halloysite nanotubes are ideal materials with large pores that can absorb the mucus barrier and are sensitive to $\mathrm{pH}$ value. In addition, the delivery system can improve the stability of lactase and enhance the permeability of drugentrapped mucosa [99]. This new microcapsule design provides a promising solution for the development of oral formulations.

\section{Discussion on transdermal drug delivery}

Transdermal drug delivery is a kind of drug delivery modus, which makes the drug enter the blood circulation through the skin and mucous membrane. The way of 
treating diseases by skin medication has a long history of application in TCM preparation. For example, the medicinal paste in TCM is a representative and early transdermal delivery system. Its unique pattern of administration determines that transdermal drug delivery has the following characteristics: (1) The first-pass effect of the liver is avoided. (2) The degradation of drugs in the gastrointestinal tract was avoided. (3) It can not only play a role of systemic therapy but also act the part of local therapy. (4) It can make the drug hold a constant blood density, and reduce the number of drug administration. (5) The method of skin administration is safe and convenient. In the literature related, partial transdermal administration is favorable for the treatment of highly localized nubbles, such as breast cancer and cervical carcinoma [99-103]. However, the efficacy of percutaneous administration is often affected by the stability of microorganisms or enzymes on the skin surface and drug particles. This prompted researchers to seek new transdermal drug technology. For example, combined nanoparticles, liposomes, microspheres and another nano-sized particles with transdermal technology to design novel transdermal formulations can greatly improve the therapeutic effect. Toyoda et al. effectively delivered the nanogel containing antigen peptide to tumor cells through the skin by the cancer antigen inoculation test, which proved that the method of delivery antigen peptide via the skin is very beneficial to inhibit the growth of tumor [104]. The application of fresh techniques and methods provides a new research path for the transdermal drug delivery system. For example, realgar has been largely used since ancient times in the curing of various diseases, including snakebite, convulsions, and malaria. Modern research has also certificated that realgar has great potential in the treatment of various hematologic and solid tumors, such as breast cancer, granulocytic leukemia, skin cancer, etc. $[105,106]$. Similarly, water-insolubility and toxicity have always been difficult problems limiting the clinical application of realgar. Here, Qi and his team used a transdermal delivery system for the first time to deliver realgar nanoparticles and evaluated their anticancer effects and toxicity in vivo (Fig. 8E). The result indicated that compared with intraperitoneal administration, transdermal delivery of realgar nanoparticles could significantly dwindle tumor volume, with higher efficacy and lower systemic toxicity [107]. At present, there are few studies on the transdermal delivery of mineral drugs. Traditional ointments involving mineral drugs have unique therapeutic advantages and long application history. However, there are still many problems to be solved in mineral drug transdermal preparations. The mechanisms of action of most mineral drugs and their interactions with diseases, the toxicity of mineral drugs, and the accumulation of heavy metals after transdermal administration are still unclear and need to be studied. Therefore, percutaneous administration of mineral drugs is a promising and challenging direction.

\section{Conclusions}

Mineral medicines, as an integral part of the traditional medicinal culture, have been playing an important role for more than two millennia. Only $32.9 \%$ of mineral drug resources have been documented in the 2020 edition of the Chinese Pharmacopoeia [108], while mineral resources are widespread and have unique curative effects. Therefore, the development, research, and application of mineral drugs are still promising.

Mineral medicine, same as animal medicine and botanical drug, is an indispensable part of TCM. Mineral medicines have a lengthy history of application and reliable clinical efficacy. Experts in TCM of the past generations have summed up many valuable medicines' experiences and theories. Along with the advance of modern scientific knowledge, mineral medicines have also shown significant advantages in multiple malignant tumors therapy [23]. Mineral drugs commonly include heat-clearing mineral drugs (gypsum, mirabilite, realgar, etc.), hemostatic mineral drugs (ochre, alum, forged gypsum, etc.), sedative mineral drugs (cinnabar, lapis lazuli, magnetite), and insecticidal mineral drugs (cinnabar, calamine, etc.). For example, "Angong Niuhuang Pill" is an outstanding Chinese patent medicine, which mainly contains two mineral medicines of cinnabar $(\mathrm{HgS})$ and realgar $\left(\mathrm{As}_{4} \mathrm{~S}_{4}\right)$. It has been popularly used for thousands of years to cure the central nervous process and cardiovascular diseases. Modern clinical treatment for brain trauma, hemorrhage, and coma has an excellent effect [109-113]. In addition, the coronavirus pneumonia disease that broke out in 2020 is raging all over the world, threatening the life of all mankind. Surprisingly, "Lianhua Qingwen capsule" and "Qingfei paidu decoction" have achieved very positive results in anti-novel coronavirus and life-saving. And these are well-known traditional Chinese medicine prescription preparations. In the above two kinds of TCM, there is an important mineral drug: gypsum. Gypsum is outstanding for its efficacy in clearing heat-fire and promoting fluid production. And doctors of TCM have commonly applied gypsum in exogenous fever, lung heat, asthma, cough, and other diseases. Therefore, it has broad prospects for an inheritance, especially in the exploration and forthputting of mineral drugs.

However, similar to the problems encountered in the study of all TCM components, the extensive pharmacological activity and clinical efficacy of mineral medicines are still to be studied. Besides, the pharmacological mechanism still needs a lot of exploration. In addition, 
the safety of mineral drugs is still the bottleneck in their development as a result that most mineral drugs contain a large number of heavy metals. For example, cinnabar is often used to treat neurological diseases [114-116]. And reports indicate that cinnabar and its main component $\mathrm{HgS}$ have low cytotoxicity. In in vitro experiments, the survival rate of cells in the environment of large-dose cinnabar and $\mathrm{HgS}$ is about $65 \%$, higher than $\mathrm{HgCl}_{2}$ and $\mathrm{MeHg}$. That means cinnabar has no significant effect on the intracellular mercury content [117]. However, studies have pointed out that even therapeutic doses of cinnabar have potential neurotoxicity [118]. Studies have pointed out that the cure and venom dosage of cinnabar have distinct pathways and targets in the cerebral cortex [114]. Moreover, the latent molecular mechanism of the pharmacodynamics and toxicological activities of cinnabar is still being explored. Some traditional mineral medicines in TCM are not used as medicines to play a therapeutic role in modern applications. Such as magnetite as a contrast agent component in the imaging of early atherosclerotic lesions [119]. This provides us with a very promising idea for the development of new pharmaceutical excipients, which embodies the advantages of the combination of TCM and accessories. Although there are some limitations in the methods of studying the pharmacological action and mechanism of a single mineral component. Considering that the mineral component is small and relatively simple, this research idea can also provide some references for the further study of mineral drugs [119].

At present, many works of literature have given an account of the therapeutic effects of the mineral drugs in a variety of malignant tumors, such as in the therapeutics of promyelocytic leukemia, gastric cancer, etc [120-124]. However, the safety issues such as heavy metals and hazardous elements in mineral drugs still limit the clinical use of mineral drugs. For example, the existing mineral preparations such as Daqi Li powder, Jiuhua ointment, and Half-sulfur pills on the market have shown therapeutic effects in removing blood stasis and swelling, repairing skin wounds. However, even at the dosage used, mineral medicines still unavoidably have certain hepatotoxicity and nephrotoxicity, as well as the accumulation of heavy metals. Therefore, it is very necessary for the development and utilization of mineral medicines to optimize mineral medicine preparations, improve the curative effects, and reduce toxicity by taking advantage of modern preparations.

New drug delivery systems and formulation technologies have established strategies for the study of mineral drugs in TCM, enabling many breakthroughs in the development and utilization of mineral drugs. The application of nanocarriers and biomaterials provides feasible opportunities for the construction of mineral drug nano-delivery platforms. Liposomes, exosomes, and polymer nanoparticles are widely used in nano-medicine for their superior biocompatibility. And they can be effectively designed as carrier materials for transporting mineral nanoparticles. It provides more possibilities for mineral drugs to play a therapeutic role. And they can be effectively designed as carrier materials for transporting mineral nanoparticles. It provides more possibilities for mineral drugs to play a therapeutic role. On the other hand, the unique properties and structures of mineral drugs have also shown great latent in the study of drug delivery carriers. Such as silicon dioxide coating which can protect insulin-loaded liposomes from degradation by digestive enzymes [16]. And another, calcium sulfate supports vancomycin nano-systems, which can significantly enhance their antibacterial properties [125].

So far, more studies on arsenic and iron preparations have been reported. The establishment of novel drug delivery systems greatly improves the drug loading and targeting of ATO, while the research on iron is mainly in MRI imaging ability and carrier research. Recently, many pharmacological activities of magnetic targeting systems have shown significant advantages, and iron minerals such as iron oxide have been further studied as drugs and carriers. In addition, in the design of mineral medicine preparations, due to the reduction in the amount of mineral medicine used, it is also possible to choose another medicine to match it. Under the synergistic treatment, it can better exert the efficacy of mineral medicine itself and reduce the dose toxicity, which is not only safer to use, but also effective even better.

In this review, we systematically describe the chemical constituents, pharmacological actions, and applications in delivery systems of mineral drugs of Chinese medicine, such as preparing multifunctional nanoparticles to deliver ATO to heighten the treatment of HCC. Despite the significant achievements in the research of mineral medicines delivery systems, there are still exist some challenges. The toxicity and safety of mineral drugs are still the focus of attention, and the more efficient and safe delivery matrix needs to be excavated. In addition, this review focuses on the research achievements of TCM mineral drugs in transport systems, including the curing of malignant burls and the progress in delivery vehicles. It is expected to overcome the defects of poor solubility, low bioavailability, and strong toxicity of TCM. Hopefully, under the reference of this article, it can help to tap more potential of mineral drugs in the research of drug delivery systems. Whether as medicaments or nanodelivery vehicles, we are all willing and eager to witness that. 


\section{Abbreviations}

AML: Acute myeloid leukemia; ANG: Angiopep-2; APL: Acute promyelocytic leukemia; ATF: Amino-terminal fragment; ATO: Arsenic trioxide; ATRA : All-trans retinoic acid; BBB: Blood-brain barrier; BHD: Bai-Hu decoction; BSA: Bovine serum albumin; BSM: Basilicum seed mucilage; CPX: Cephalexin; DCQD: Dachengqi decoction; DOX: Doxorubicin; EGCG: (-)-Epigallocatechin3-gallate; FA: Folic acid; Gem: Gemcitabine; Gos: Gossypol; HBMEC: Human brain microvascular endothelial cells; HBV: Hepatitis B virus; HCC: Hepatocellular carcinoma; ICP-OES: Inductively coupled plasma optical emission spectrometry; IL-17: Interleukin-17; IL-1 $\beta$ : Interleukin-1 $\beta$; IONPs: Iron oxide nanoparticles; iRGD: Internalizing RGD; LIP: Liposomes; LO2: Normal human hepatocytes; MAN: Mannose; MDT: Magnetic drug targeting; MFH: Magnetic fluid hyperthermia; MLs: Magnetoliposomes; M-LPMSN: Magnetic large-pore mesoporous silica nanoparticles; MNHGs: Magnetic nano-hydrogels; MNPs: Magnetic nanoparticles; MRI: Magnetic resonance imaging; MSN: Mesoporous silica nanoparticles; MTT: Methyl thiazolyl tetrazolium; NPs: Nanoparticles; PAA: Polyacrylic acid; PCM: Phase change material; PEG: Polyethylene glycol; PLC: Polyethylene glycol and lactobionic acid modified chitosan; PLGA: Poly(lactide-co-glycolide) acid; RA: Retinoic acid; RNPs: Realgar nanoparticles; scFv: Single chain variable fragment; TCM: Traditional Chinese medicine; TNF-a: Tumor necrosis factor-a; TNF: Tumor necrosis factor; TPP: Triphenylphosphine.

\section{Acknowledgements}

Not applicable.

\section{Authors' contributions}

XZ: Investigation, Software, Writing —original draft. ZD: Software, Validation, Writing —original draft. YX: Software, Validation, QL: Writing_original draft, KF: Writing —original draft, YZ: Writing — review and editing, LD: Conceptualization, Resources, Writing — review and editing, Project administration. RW: Conceptualization, Supervision, Resources, Writing — review and editing, Project administration. All authors read and approved the final manuscript.

\section{Funding}

This article is supported by the National Natural Science Foundation of China (No. 81903557, 82074024), Natural Science Foundation of Jiangsu Province (No. BK20190802), Natural Science Foundation Youth Project of Nanjing University of Chinese Medicine (No. NZY81903557), the Open Project of Chinese Materia Medica First-Class Discipline of Nanjing University of Chinese Medicine (No. 2020YLXK019), and College Students'Innovative Entrepreneurial Training of Nanjing University of Chinese Medicine (No. $202110315097 Z$ and 202110315021).

\section{Availability of data and materials \\ Not applicable.}

\section{Declarations}

Ethics approval and consent to participate

Not applicable.

\section{Consent for publication}

Not applicable.

\section{Competing interests}

The authors declare that they have no competing interests.

\section{Author details}

${ }^{1}$ College of Pharmacy, Nanjing University of Chinese Medicine, Nanjing 210023, China. ${ }^{2}$ Jiangsu Provincial TCM Engineering Technology Research Center of High Efficient Drug Delivery System, Nanjing 210023, China.

Received: 7 November 2021 Accepted: 28 January 2022 Published online: 10 February 2022

\footnotetext{
References

1. Ettlinger R, Moreno N, Volkmer D, Kerl K, Bunzen H. Zeolitic imidazolate framework-8 as pH-sensitive nanocarrier for "Arsenic Trioxide" drug
}

delivery. Chemistry. 2019;25(57):13189-96. https://doi.org/10.1002/ chem.201902599 (Epub 2019 Sep 13).

2. Jin Z, Yi X, Yang J, Zhou M, Wu P, Yan G. Liposome-coated arsenic-manganese complex for magnetic resonance imaging-guided synergistic therapy against carcinoma. Int J Nanomed. 2021;1(16):3775-88. https:// doi.org/10.2147/IJN.S313962.

3. Song X, Wang J, Xu Y, Shao H, Gu J. Surface-modified PLGA nanoparticles with PEG/LA-chitosan for targeted delivery of arsenic trioxide for liver cancer treatment: inhibition effects enhanced and side effects reduced. Colloids Surf B Biointerfaces. 2019;1(180):110-7. https://doi. org/10.1016/j.colsurfb.2019.04.036 (Epub 2019 Apr 16).

4. Song P, Hai Y, Wang X, Zhao L, Chen B, Cui P, Xie Q, Yu L, Li Y, Wu Z, Li $H$. Realgar transforming solution suppresses angiogenesis and tumor growth by inhibiting VEGF receptor 2 signaling in vein endothelial cells. Arch Pharm Res. 2018;41(4):467-80. https://doi.org/10.1007/s12272018-1014-6 (Epub 2018 Mar 15).

5. Rayegan A, Allafchian A, Abdolhosseini Sarsari I, Kameli P. Synthesis and characterization of basil seed mucilage coated $\mathrm{Fe}_{3} \mathrm{O}_{4}$ magnetic nanoparticles as a drug carrier for the controlled delivery of cephalexin. Int J Biol Macromol. 2018;1(113):317-28. https://doi.org/10.1016/j.jibio mac.2018.02.134 (Epub 2018 Feb 23).

6. Liu R, Li X, Huang N, Fan M, Sun R. Toxicity of traditional Chinese medicine herbal and mineral products. Adv Pharmacol. 2020;87:301-46. https://doi.org/10.1016/bs.apha.2019.08.001 (Epub 2019 Oct 18).

7. Khalifehzadeh $\mathrm{R}$, Arami H. Biodegradable calcium phosphate nanoparticles for cancer therapy. Adv Colloid Interface Sci. 2020;279:102157. https://doi.org/10.1016/j.cis.2020.102157 (Epub 2020 Apr 10).

8. Palanisamy S, Wang YM. Superparamagnetic iron oxide nanoparticulate system: synthesis, targeting, drug delivery and therapy in cancer. Dalton Trans. 2019;48(26):9490-515. https://doi.org/10.1039/c9dt00459a.

9. Das M, Solanki A, Joshi A, Devkar R, Seshadri S, Thakore S. $\beta$-cyclodextrin based dual-responsive multifunctional nanotheranostics for cancer cell targeting and dual drug delivery. Carbohydr Polym. 2019;15(206):694705. https://doi.org/10.1016/j.carbpol.2018.11.049 (Epub 2018 Nov 20).

10. Rafiee F, Haghi F, Bikas R, Heidari A, Gholami M, Kozakiewicz A, Zeighami $H$. Synthesis, characterization and assessment of anti-quorum sensing activity of copper(II)-ciprofloxacin complex against Pseudomonas aeruginosa PAO1. AMB Express. 2020;10(1):82. https://doi.org/10.1186/ s13568-020-01017-3.

11. Yin M, Lin X, Ren T, Li Z, Ren X, Huang TS. Cytocompatible quaternized carboxymethyl chitosan/poly(vinyl alcohol) blend film loaded copper for antibacterial application. Int J Biol Macromol. 2018;120(Pt A):992-8. https://doi.org/10.1016/j.ijbiomac.2018.08.105 (Epub 2018 Aug 31).

12. Hildebrand S, Löwa N, Paysen H, Fratila RM, Reverte-Salisa L, Trakoolwilaiwan T, Niu Z, Kasparis G, Preuss SF, Kosch O, de la Fuente MJ, Thanh NTK, Wiekhorst F, Pfeifer A. Quantification of lipoprotein uptake in vivo using magnetic particle imaging and spectroscopy. ACS Nano. 2021;15(1):434-46. https://doi.org/10.1021/acsnano.0c03229 (Epub 2020 Dec 11).

13. Zhou J, Hou J, Liu Y, Rao J. Targeted delivery of $\beta$-glucosidase-loaded magnetic nanoparticles: effect of external magnetic field duration and intensity. Nanomedicine (Lond). 2020;15(21):2029-40. https://doi.org/ 10.2217/nnm-2020-0186 (Epub 2020 Sep 4).

14. Wahajuddin AS. Superparamagnetic iron oxide nanoparticles: magnetic nanoplatforms as drug carriers. Int J Nanomed. 2012;7:3445-71. https:// doi.org/10.2147/IJN.S30320.

15. Xu JK, Zhang FF, Sun JJ, Sheng J, Wang F, Sun M. Bio and nanomaterials based on $\mathrm{Fe}_{3} \mathrm{O}_{4}$. Molecules. 2014;19(12):21506-28. https://doi.org/10. 3390/molecules191221506.

16. Mohanraj VJ, Barnes TJ, Prestidge CA. Silica nanoparticle coated liposomes: a new type of hybrid nanocapsule for proteins. Int J Pharm. 2010;392(1-2):285-93. https://doi.org/10.1016/j.jpharm.2010.03.061 (Epub 2010 Apr 2)

17. Ingle SG, Pai RV, Monpara JD, Vavia PR. Liposils: an effective strategy for stabilizing Paclitaxel loaded liposomes by surface coating with silica. Eur J Pharm Sci. 2018;15(122):51-63. https://doi.org/10.1016/j.ejps.2018. 06.025 (Epub 2018 Jun 21).

18. Amin MU, Ali S, Ali MY, Tariq I, Nasrullah U, Pinnapreddy SR, Wölk C, Bakowsky U, Brüßler J. Enhanced efficacy and drug delivery with lipid coated mesoporous silica nanoparticles in cancer therapy. Eur J Pharm 
Biopharm. 2021;165:31-40. https://doi.org/10.1016/j.ejpb.2021.04.020 (Epub 2021 May 4).

19. Meng H, Wang M, Liu H, Liu X, Situ A, Wu B, Ji Z, Chang CH, Nel AE. Use of a lipid-coated mesoporous silica nanoparticle platform for synergistic gemcitabine and paclitaxel delivery to human pancreatic cancer in mice. ACS Nano. 2015;9(4):3540-57. https://doi.org/10.1021/acsna no. 5 b00510 (Epub 2015 Mar 31. Erratum in: ACS Nano. 2016 Jun 28;10(6):6416).

20. Lü P, Li X, Chen JW. Study on the speciation of calcium in Baihu decoction. Guang Pu Xue Yu Guang Pu Fen Xi. 2010;30(10):2824-6 (Chinese).

21. Jia LL, Li R, Ma J, Fan Y, Li HB. Effects of Bai-Hu decoction on fever induced by lipopolysaccharide. Kaohsiung J Med Sci. 2013;29(3):12832. https://doi.org/10.1016/j.kjms.2012.08.022 (Epub 2013 Jan 31).

22. Xiong XJ. Exploration of Baihu Jia Renshen Decoction formula syndromes based on severe cases of critical care and integrative medicine and its clinical efficacy on clearing heat, elevating blood pressure, curing hypertonic and lowering blood sugar. Zhongguo Zhong Yao Za Zhi. 2019;44(18):3861-8. https://doi.org/10.19540/j.cnki.cjcmm.20190 416.502 (Chinese).

23. Chen H, Pan T, Liu P, Wang P, Xu S. Baihu Jia Guizhi decoction improves rheumatoid arthritis inflammation by regulating Succinate/SUCNR1 metabolic signaling pathway. Evid Based Complement Alternat Med. 2019;26(2019):3258572. https://doi.org/10.1155/2019/3258572.

24. Gong HL, Tang WF, Wang J, Chen GY, Huang X. Effect of formula compatibility on the pharmacokinetics of components from Dachengqi Decoction [See Text] in rats. Chin J Integr Med. 2012;18(9):708-13. https://doi.org/10.1007/s11655-012-1205-9 (Epub 2012 Aug 31)

25. Liu G, Liu F, Xiao L, Kuang Q, He X, Wang Y, Wang Y. Narrative review of the mechanisms of action of dachengqi decoction in the treatment of hyperlipidemic pancreatitis on six-hollow-organs to be unblocked theory. Ann Palliat Med. 2020;9(4):2323-9. https://doi.org/10.21037/ apm-20-1332 (Epub 2020 Jul 20).

26. Sun W, Chen Y, Li H, Liu H, Li J, Chen J, Feng D. Material basis and molecular mechanisms of Dachengqi decoction in the treatment of acute pancreatitis based on network pharmacology. Biomed Pharmacother. 2020;121: 109656. https://doi.org/10.1016/j.biopha.2019.109656 (Epub 2019 Nov 23).

27. Liu G, Liu F, Xiao L, Kuang Q, He X, Wang Y, Yu Y. Treatment of hyperlipidemic acute pancreatitis with modified Dachengqi decoction combining with conventional therapy based on "six-hollow-organs to be unblocked" theory. Ann Palliat Med. 2020;9(4):2045-53. https://doi. org/10.21037/apm-20-1106 (Epub 2020 Jul 20)

28. Ma S, Liu C, Li B, Zhang T, Jiang L, Wang R. Sonophoresis enhanced transdermal delivery of cisplatin in the xenografted tumor model of cervical cancer. Onco Targets Ther. 2020;29(13):889-902. https://doi. org/10.2147/OTT.S238126.

29. Pei L, Shen X, Yan Y, Tan C, Qu K, Zou J, Wang Y, Ping F. Virtual screening of the multi-pathway and multi-gene regulatory molecular mechanism of dachengqi decoction in the treatment of stroke based on network pharmacology. Comb Chem High Throughput Screen. 2020;23(8):77587. https://doi.org/10.2174/1386207323666200311113747.

30. Zeng P, Wang XM, Su HF, Zhang T, Ning LN, Shi Y, Yang SS, Lin L, Tian Q. Protective effects of Da-cheng-qi decoction in rats with intracerebral hemorrhage. Phytomedicine. 2021;90: 153630. https://doi.org/10. 1016/j.phymed.2021.153630 (Epub 2021 Jun 17).

31. Zhang KJ, Zhu JZ, Bao XY, Zheng Q, Zheng GQ, Wang Y. Shexiang baoxin pills for coronary heart disease in animal models: preclinical evidence and promoting angiogenesis mechanism. Front Pharmacol. 2017;28(8):404. https://doi.org/10.3389/fphar.2017.00404.

32. Stahl M, Tallman MS. Acute promyelocytic leukemia (APL): remaining challenges towards a cure for all. Leuk Lymphoma. 2019;60(13):310715. https://doi.org/10.1080/10428194.2019.1613540 (Epub 2019 Dec 16)

33. Mannan A, Muhsen IN, Barragán E, Sanz MA, Mohty M, Hashmi SK, Aljurf M. Genotypic and phenotypic characteristics of acute promyelocytic leukemia translocation variants. Hematol Oncol Stem Cell Ther 2020;13(4):189-201. https://doi.org/10.1016/j.hemonc.2020.05.007 (Epub 2020 May 20)

34. Hai Y, Wang X, Song P, Li JY, Zhao LH, Xie F, Tan XM, Xie QJ, Yu L, Li Y, Wu ZR, Li HY. Realgar transforming solution-induced differentiation of NB4 cell by the degradation of PML/RARa partially through the ubiquitin-proteasome pathway. Arch Pharm Res. 2019;42(8):684-94. https://doi.org/10.1007/s12272-019-01170-9 (Epub 2019 Jun 18).

35. Gurnari C, De Bellis E, Divona M, Ottone T, Lavorgna S, Voso MT. When poisons cure: the case of arsenic in acute promyelocytic leukemia. Chemotherapy. 2019;64(5-6):238-47. https://doi.org/10.1159/00050 7805 (Epub 2020 Jun 10).

36. Ablain J, Rice K, Soilihi H, de Reynies A, Minucci S, de Thé H. Activation of a promyelocytic leukemia-tumor protein 53 axis underlies acute promyelocytic leukemia cure. Nat Med. 2014;20(2):167-74. https://doi. org/10.1038/nm.3441 (Epub 2014 Jan 12).

37. Korf K, Wodrich H, Haschke A, Ocampo C, Harder L, Gieseke F, Pollmann A, Dierck K, Prall S, Staege H, Ma H, Horstmann MA, Evans RM, Sternsdorf T. The PML domain of PML-RARa blocks senescence to promote leukemia. Proc Natl Acad Sci USA. 2014;111(33):12133-8. https://doi. org/10.1073/pnas.1412944111 (Epub 2014 Aug 4)

38. Cicconi L, Fenaux P, Kantarjian H, Tallman M, Sanz MA, Lo-Coco F. Molecular remission as a therapeutic objective in acute promyelocytic leukemia. Leukemia. 2018;32(8):1671-8. https://doi.org/10.1038/ s41375-018-0219-5 (Epub 2018 Jul 19).

39. Fan J, He Q, Wang Z, Huang W, Cai Z. Self-assembled nanocomplex for co-delivery of arsenic-retinoic acid prodrug into acute promyelocytic leukemia cells. J Biomed Nanotechnol. 2018;14(6):1052-65. https://doi. org/10.1166/jbn.2018.2556.

40. Zhang K, Lin H, Mao J, Luo X, Wei R, Su Z, Zhou B, Li D, Gao J, Shan $H$. An extracellular $\mathrm{pH}$-driven targeted multifunctional manganese arsenite delivery system for tumor imaging and therapy. Biomater Sci. 2019;7(6):2480-90. https://doi.org/10.1039/c9bm00216b.

41. Fan L, Liu C, Hu A, Liang J, Li F, Xiong Y, Mu CF. Dual oligopeptides modification mediates arsenic trioxide containing nanoparticles to eliminate primitive chronic myeloid leukemia cells inside bone marrow niches. Int J Pharm. 2020:579:119179. https://doi.org/10.1016/j.ijpharm.2020. 119179 (Epub 2020 Feb 26).

42. Fang $Y$, Zhang Z. Arsenic trioxide as a novel anti-glioma drug: a review. Cell Mol Biol Lett. 2020;24(25):44. https://doi.org/10.1186/ s11658-020-00236-7.

43. Milano MT, Johnson MD, Sul J, Mohile NA, Korones DN, Okunieff P, Walter KA. Primary spinal cord glioma: a surveillance, epidemiology, and end results database study. J Neurooncol. 2010;98(1):83-92. https://doi. org/10.1007/s1 1060-009-0054-7 (Epub 2009 Nov 7).

44. Becker KP, Yu J. Status quo_-standard-of-care medical and radiation therapy for glioblastoma. Cancer J. 2012;18(1):12-9. https://doi.org/10. 1097/PPO.0b013e318244d7eb.

45. Osuka S. Global trends in pre-clinical research on malignant glioma. No Shinkei Geka. 2021;49(3):485-9. https://doi.org/10.11477/mf.14362 04420 (Japanese).

46. Ning S, Knox SJ. Optimization of combination therapy of arsenic trioxide and fractionated radiotherapy for malignant glioma. Int J Radiat Oncol Biol Phys. 2006;65(2):493-8. https://doi.org/10.1016/j.jirobp.2005. 12.015 (Epub 2006 Mar 24).

47. Sun Y, Wang C, Wang L, Dai Z, Yang K. Arsenic trioxide induces apoptosis and the formation of reactive oxygen species in rat glioma cells. Cell Mol Biol Lett. 2018;27(23):13. https://doi.org/10.1186/ s11658-018-0074-4

48. Tao J, Fei W, Tang H, Li C, Mu C, Zheng H, Li F, Zhu Z. Angiopep-2-conjugated "Core-Shell" hybrid nanovehicles for targeted and $\mathrm{pH}$-triggered delivery of arsenic trioxide into glioma. Mol Pharm. 2019;16(2):786-97. https://doi.org/10.1021/acs.molpharmaceut.8b01056 (Epub 2019 Jan 24).

49. Wang N, Zhang W, Hu D, Jiang L, Liu X, Tang S, Zhou X, Liu T, Tang X, Chai Y, Li M, Peng H, Du Z.'Prodrug-Like' acetylmannosamine modified liposomes loaded with arsenic trioxide for the treatment of orthotopic glioma in mice. J Pharm Sci. 2020;109(9):2861-73. https://doi.org/10. 1016/j.xphs.2020.06.001 (Epub 2020 Jun 11).

50. Linder B, Wehle A, Hehlgans S, Bonn F, Dikic I, Rödel F, Seifert V, Kögel D. Arsenic trioxide and (-)-gossypol synergistically target glioma stem-like cells via inhibition of hedgehog and notch signaling. Cancers (Basel). 2019;11(3):350. https://doi.org/10.3390/cancers11030350.

51. LuY, Han S, Zheng H, Ma R, Ping Y, Zou J, Tang H, Zhang Y, Xu X, Li F. A novel RGDyC/PEG co-modified PAMAM dendrimer-loaded arsenic trioxide of glioma targeting delivery system. Int J Nanomed. 2018;2(13):5937-52. https://doi.org/10.2147/IJN.S175418. 
52. Shi X, Ma R, Lu Y, Cheng Y, Fan X, Zou J, Zheng H, Li F, Piao JG. iRGD and TGN CO-modified PAMAM for multi-targeted delivery of ATO to gliomas. Biochem Biophys Res Commun. 2020;527(1):117-23. https://doi.org/10. 1016/j.bbrc.2020.04.064 (Epub 2020 Apr 28).

53. Hartke J, Johnson M, Ghabril M. The diagnosis and treatment of hepatocellular carcinoma. Semin Diagn Pathol. 2017;34(2):153-9. https://doi. org/10.1053/j.semdp.2016.12.011 (Epub 2016 Dec 20).

54. Sim HW, Knox J. Hepatocellular carcinoma in the era of immunotherapy. Curr Probl Cancer. 2018;42(1):40-8. https://doi.org/10.1016/j.currp roblcancer.2017.10.007 (Epub 2017 Nov 15).

55. Jiang Y, Han Q, Zhao H, Zhang J. The mechanisms of HBV-induced hepatocellular carcinoma. J Hepatocell Carcinoma. 2021;20(8):435-50. https://doi.org/10.2147/JHC.S307962.

56. Kim SS, Lee S, Kim MJ. Prognostic factors of gadoxetic acid-enhanced MRI for postsurgical outcomes in multicentric hepatocellular carcinoma. Eur Radiol. 2021;31(5):3405-16. https://doi.org/10.1007/s00330020-07419-y (Epub 2020 Nov 4).

57. Sadaf N, Kumar N, Ali M, Ali V, Bimal S, Haque R. Arsenic trioxide induces apoptosis and inhibits the growth of human liver cancer cells. Life Sci. 2018;15(205):9-17. https://doi.org/10.1016/j.lfs.2018.05.006 (Epub 2018 May 5).

58. Swindell EP, Hankins PL, Chen H, Miodragović DU, O'Halloran TV. Anticancer activity of small-molecule and nanoparticulate arsenic(III) complexes. Inorg Chem. 2013;52(21):12292-304. https://doi.org/10. 1021/ic401211u (Epub 2013 Oct 22).

59. Shooshtary S, Behtash S, Nafisi S. Arsenic trioxide binding to serum proteins. J Photochem Photobiol B. 2015;148:31-6. https://doi.org/10. 1016/j.jphotobiol.2015.03.001 (Epub 2015 Apr 1).

60. Kong D, Jiang T, Liu J, Jiang X, Liu B, Lou C, Zhao B, Carroll SL, Feng G. Chemoembolizing hepatocellular carcinoma with microsphere cored with arsenic trioxide microcrystal. Drug Deliv. 2020;27(1):1729-40. https://doi.org/10.1080/10717544.2020.1856219.

61. Wu Q, Chen X, Wang P, Wu Q, Qi X, Han X, Chen L, Meng X, Xu K. Delivery of arsenic trioxide by multifunction nanoparticles to improve the treatment of hepatocellular carcinoma. ACS Appl Mater Interfaces. 2020;12(7):8016-29. https://doi.org/10.1021/acsami.9b22802 (Epub 2020 Feb 10)

62. Eslahi M, Dana PM, Asemi Z, Hallajzadeh J, Mansournia MA, Yousefi B. The effects of chitosan-based materials on glioma: Recent advances in its applications for diagnosis and treatment. Int J Biol Macromol. 2021;31(168):124-9. https://doi.org/10.1016/j.ijbiomac.2020.11.180 (Epub 2020 Dec 1)

63. Chi X, Zhang R, Zhao T, Gong X, Wei R, Yin Z, Lin H, Li D, Shan H, Gao J. Targeted arsenite-loaded magnetic multifunctional nanoparticles for treatment of hepatocellular carcinoma. Nanotechnology. 2019;30(17):175101. https://doi.org/10.1088/1361-6528/aaff9e (Epub 2019 Jan 17)

64. Akhtar A, Ghali L, Wang SX, Bell C, Li D, Wen X. Optimisation of folate-mediated liposomal encapsulated arsenic trioxide for treating HPV-positive cervical cancer cells in vitro. Int J Mol Sci. 2019;20(9):2156. https://doi.org/10.3390/ijms20092156.

65. Zhang L, Zhou Y, Kong J, Zhang L, Yuan M, Xian S, Wang Y, Cheng Y, Yang $X$. Effect of arsenic trioxide on cervical cancer and its mechanisms. Exp Ther Med. 2020;20(6):169. https://doi.org/10.3892/etm.2020.9299 (Epub 2020 Oct 9).

66. Akhtar A, Wang SX, Ghali L, Bell C, Wen X. Effective delivery of arsenic trioxide to HPV-positive cervical cancer cells using optimised liposomes: a size and charge study. Int J Mol Sci. 2018;19(4):1081. https://doi.org/10. 3390/ijms19041081.

67. Wang X, Li D, Ghali L, Xia R, Munoz LP, Garelick H, Bell C, Wen X. Therapeutic potential of delivering arsenic trioxide into HPV-infected cervical cancer cells using liposomal nanotechnology. Nanoscale Res Lett. 2016;11(1):94. https://doi.org/10.1186/s11671-016-1307-y (Epub 2016 Feb 18).

68. Qian C, Wang Y, Chen Y, Zeng L, Zhang Q, Shuai X, Huang K. Suppression of pancreatic tumor growth by targeted arsenic delivery with antiCD44v6 single chain antibody conjugated nanoparticles. Biomaterials. 2013;34(26):6175-84. https://doi.org/10.1016/j.biomaterials.2013.04.056 (Epub 2013 May 27)

69. Hajipour H, Hamishehkar H, Nazari Soltan Ahmad S, Barghi S, Maroufi NF, Taheri RA. Improved anticancer effects of epigallocatechin gallate using RGD-containing nanostructured lipid carriers. Artif Cells Nanomed Biotechnol. 2018;46(Suppl 1):283-92. https://doi.org/10. 1080/21691401.2017.1423493 (Epub 2018 Jan 8)

70. Fang W, Peng ZL, Dai YJ, Wang DL, Huang P, Huang HP. (-)-Epigallocatechin-3-gallate encapsulated realgar nanoparticles exhibit enhanced anticancer therapeutic efficacy against acute promyelocytic leukemia. Drug Deliv. 2019;26(1):1058-67. https://doi.org/10.1080/10717544. 2019.1672830.

71. Huang X, Lin C, Luo C, Guo Y, Li J, Wang Y, Xu J, Zhang Y, Wang H, Liu Z Chen $\mathrm{B} . \mathrm{Fe}_{3} \mathrm{O}_{4} @ \mathrm{M}$ nanoparticles for MRI-targeted detection in the early lesions of atherosclerosis. Nanomedicine. 2021;33: 102348. https://doi. org/10.1016/j.nano.2020.102348 (Epub 2020 Dec 13).

72. Jin Q, Liu J, Zhu W, Dong Z, Liu Z, Cheng L. Albumin-assisted synthesis of ultrasmall FeS2 nanodots for imaging-guided photothermal enhanced photodynamic therapy. ACS Appl Mater Interfaces. 2018;10(1):332-40. https://doi.org/10.1021/acsami.7b16890 (Epub 2017 Dec 19).

73. Fei W, Li C, Tao J, Cai X, Yao W, Ye Y, Zhang Y, Yao Y, Song Q, Li F, Zheng C. Construction of arsenic-metal complexes loaded nanodrugs for solid tumor therapy: a mini review. Int J Pharm. 2020;583:119385. https://doi. org/10.1016/j.jpharm.2020.119385 (Epub 2020 May 4).

74. El-Boubbou K. Magnetic iron oxide nanoparticles as drug carriers: clinical relevance. Nanomedicine (Lond). 2018;13(8):953-71. https://doi.org/ 10.2217/nnm-2017-0336 (Epub 2018 Jan 29).

75. El-Boubbou K. Magnetic iron oxide nanoparticles as drug carriers: preparation, conjugation and delivery. Nanomedicine (Lond). 2018;13(8):929-52. https://doi.org/10.2217/nnm-2017-0320 (Epub 2018 Mar 16).

76. Kim DH, Guo Y, Zhang Z, Procissi D, Nicolai J, Omary RA, Larson AC. Temperature-sensitive magnetic drug carriers for concurrent gemcitabine chemohyperthermia. Adv Healthc Mater. 2014;3(5):714-24. https://doi. org/10.1002/adhm.201300209 (Epub 2013 Oct 21).

77. Gholami A, Mousavi SM, Hashemi SA, Ghasemi Y, Chiang WH, Parvin N. Current trends in chemical modifications of magnetic nanoparticles for targeted drug delivery in cancer chemotherapy. Drug Metab Rev. 2020;52(1):205-24. https://doi.org/10.1080/03602532.2020.1726943 (Epub 2020 Feb 21).

78. Lee GY, Qian WP, Wang L, Wang YA, Staley CA, Satpathy M, Nie S, Mao H, Yang $L$. Theranostic nanoparticles with controlled release of gemcitabine for targeted therapy and MRI of pancreatic cancer. ACS Nano. 2013;7(3):2078-89. https://doi.org/10.1021/nn3043463 (Epub 2013 Mar 12).

79. Yang R, An Y, Miao F, Li M, Liu P, Tang Q. Preparation of folic acid-conjugated, doxorubicin-loaded, magnetic bovine serum albumin nanospheres and their antitumor effects in vitro and in vivo. Int J Nanomed. 2014;4(9):4231-43. https://doi.org/10.2147/IJN.S67210.

80. Lee J, Kim H, Kim S, Lee H, Kim J, Kim N, et al. A multifunctional mesoporous nanocontainer with an iron oxide core and a cyclodextrin gatekeeper for an efficient theranostic platform. J Mater Chem. 2012;22(28):14061-7.

81. Choi GE, Kang MS, Kim YJ, Yoon JJ, Jeong YI. Magnetically responsive drug delivery using doxorubicin and iron oxide nanoparticle-incorporated lipocomplexes. J Nanosci Nanotechnol. 2019;19(2):675-9. https:// doi.org/10.1166/jnn.2019.15910.

82. Ketkar-Atre A, Struys T, Dresselaers T, Hodenius M, Mannaerts I, Ni Y, Lambrichts I, Van Grunsven LA, De Cuyper M, Himmelreich U. In vivo hepatocyte MR imaging using lactose functionalized magnetoliposomes. Biomaterials. 2014;35(3):1015-24. https://doi.org/10.1016/j. biomaterials.2013.10.029 (Epub 2013 Nov 5).

83. Soenen SJ, Velde GV, Ketkar-Atre A, Himmelreich U, De Cuyper M. Magnetoliposomes as magnetic resonance imaging contrast agents. Wiley Interdiscip Rev Nanomed Nanobiotechnol. 2011;3(2):197-211. https:// doi.org/10.1002/wnan.122.

84. Millart E, Lesieur S, Faivre V. Superparamagnetic lipid-based hybrid nanosystems for drug delivery. Expert Opin Drug Deliv. 2018;15(5):52340. https://doi.org/10.1080/17425247.2018.1453804 (Epub 2018 Mar 29).

85. Li B, Li B, He D, Feng C, Luo Z, He M. Preparation, characterization, and in vitro $\mathrm{pH}$-sensitivity evaluation of superparamagnetic iron oxide nanoparticle- misonidazole $\mathrm{pH}$-sensitive liposomes. Curr Drug Deliv. 
2019;16(3):254-67. https://doi.org/10.2174/15672018166661811141 24333.

86. Zhu C, Yang H, Shen L, Zheng Z, Zhao S, Li Q, Yu F, Cen L. Microfluidic preparation of PLGA microspheres as cell carriers with sustainable Rapa release. J Biomater Sci Polym Ed. 2019;30(9):737-55. https://doi.org/10. 1080/09205063.2019.1602930 (Epub 2019 Apr 19).

87. Ramazani F, Chen W, van Nostrum CF, Storm G, Kiessling F, Lammers T, Hennink WE, Kok RJ. Strategies for encapsulation of small hydrophilic and amphiphilic drugs in PLGA microspheres: state-of-the-art and challenges. Int J Pharm. 2016;499(1-2):358-67. https://doi.org/10.1016/j. ijpharm.2016.01.020 (Epub 2016 Jan 12).

88. Wei Y, Wu Y, Wen K, Bazybek N, Ma G. Recent research and development of local anesthetic-loaded microspheres. J Mater Chem B. 2020;8(30):6322-32. https://doi.org/10.1039/d0tb01129k.

89. Ayyanaar S, Kesavan MP, Balachandran C, Rasala S, Rameshkumar P, Aoki S, Rajesh J, Webster TJ, Rajagopal G. Iron oxide nanoparticle core-shell magnetic microspheres: applications toward targeted drug delivery. Nanomedicine. 2020;24: 102134. https://doi.org/10.1016/j.nano.2019. 102134 (Epub 2019 Dec 10).

90. Poorgholy N, Massoumi B, Ghorbani M, Jaymand M, Hamishehkar $\mathrm{H}$. Intelligent anticancer drug delivery performances of two poly $(\mathrm{N}$ isopropylacrylamide)-based magnetite nanohydrogels. Drug Dev Ind Pharm. 2018;44(8):1254-61. https://doi.org/10.1080/03639045.2018. 1442845 (Epub 2018 Feb 27).

91. Zhao Y, Onda K, Yuan B, Tanaka S, Kiyomi A, Sugiyama K, Sugiura M, Takagi N, Hirano T. Arsenic disulfide-induced apoptosis and its potential mechanism in two- and three-dimensionally cultured human breast cancer MCF-7 cells. Int J Oncol. 2018;52(6):1959-71. https://doi.org/10. 3892/ijo.2018.4357 (Epub 2018 Apr 4).

92. Mody KT, Popat A, Mahony D, Cavallaro AS, Yu C, Mitter N. Mesoporous silica nanoparticles as antigen carriers and adjuvants for vaccine delivery. Nanoscale. 2013;5(12):5167-79. https://doi.org/10.1039/c3nro 0357d.

93. Manshadi MKD, Saadat M, Mohammadi M, Kamali R, Shamsi M, Naseh M, Sanati-Nezhad A. Magnetic aerosol drug targeting in lung cancer therapy using permanent magnet. Drug Deliv. 2019;26(1):120-8. https://doi.org/10.1080/10717544.2018.1561765.

94. Lvov YM, Shchukin DG, Möhwald H, Price RR. Halloysite clay nanotubes for controlled release of protective agents. ACS Nano. 2008;2(5):814-20. https://doi.org/10.1021/nn800259q.

95. Abdullayev E, Lvov Y. Halloysite clay nanotubes for controlled release of protective agents. J Nanosci Nanotechnol. 2011;11(11):10007-26. https://doi.org/10.1166/jnn.2011.5724.

96. Vergaro V, Lvov YM, Leporatti S. Halloysite clay nanotubes for resveratrol delivery to cancer cells. Macromol Biosci. 2012;12(9):1265-71. https:// doi.org/10.1002/mabi.201200121 (Epub 2012 Aug 8).

97. Lisuzzo L, Cavallaro G, Milioto S, Lazzara G. Halloysite nanotubes coated by chitosan for the controlled release of khellin. Polymers (Basel). 2020;12(8):1766. https://doi.org/10.3390/polym12081766.

98. Homayun B, Choi HJ. Halloysite nanotube-embedded microparticles for intestine-targeted co-delivery of biopharmaceuticals. Int J Pharm. 2020;579:119152. https://doi.org/10.1016/j.jpharm.2020.119152 (Epub 2020 Feb 17)

99. Neupane R, Boddu SHS, Abou-Dahech MS, Bachu RD, Terrero D, Babu RJ, Tiwari AK. Transdermal delivery of chemotherapeutics: strategies, requirements, and opportunities. Pharmaceutics. 2021;13(7):960. https://doi.org/10.3390/pharmaceutics 13070960

100. Ma X, Jin T, Han C, Shi N, Liang G, Wen Y, Yang J, Fu X, Lan T, Jiang K, Nunes QM, Chvanov M, Criddle DN, Philips AR, Deng L, LiuT, Windsor $J A$, Sutton R, Du D, Huang W, Xia Q. Aqueous extraction from dachengqi formula granules reduces the severity of mouse acute pancreatitis via inhibition of pancreatic pro-inflammatory signalling pathways. J Ethnopharmacol. 2020;257:112861. https://doi.org/10.1016/j.jep.2020. 112861 (Epub 2020 Apr 18).

101. Atlan M, Neman J. Targeted transdermal delivery of curcumin for breast cancer prevention. Int J Environ Res Public Health. 2019;16(24):4949. https://doi.org/10.3390/ijerph16244949.

102. Lin YL, Chen CH, Wu HY, Tsai NM, Jian TY, Chang YC, Lin CH, Wu CH, Hsu FT, Leung TK, Liao KW. Inhibition of breast cancer with transdermal tamoxifen-encapsulated lipoplex. J Nanobiotechnol. 2016;19(14):11 https://doi.org/10.1186/s12951-016-0163-3.
103. Lee O, Ivancic D, Allu S, Shidfar A, Kenney K, Helenowski I, Sullivan ME, Muzzio M, Scholtens D, Chatterton RT Jr, Bethke KP, Hansen NM, Khan SA. Local transdermal therapy to the breast for breast cancer prevention and DCIS therapy: preclinical and clinical evaluation. Cancer Chemother Pharmacol. 2015;76(6):1235-46. https://doi.org/10.1007/ s00280-015-2848-y.

104. Toyoda M, Hama S, Ikeda Y, Nagasaki Y, Kogure K. Anti-cancer vaccination by transdermal delivery of antigen peptide-loaded nanogels via iontophoresis. Int J Pharm. 2015;483(1-2):110-4. https://doi.org/10. 1016/j.jpharm.2015.02.024 (Epub 2015 Feb 11).

105. Zhao Y, Onda K, Sugiyama K, Yuan B, Tanaka S, Takagi N, Hirano T. [Corrigendum] Antitumor effects of arsenic disulfide on the viability, migratory ability, apoptosis and autophagy of breast cancer cells. Oncol Rep. 2020;44(3):1293. https://doi.org/10.3892/or.2020.7653 (Epub 2020 Jun 19. Erratum for: Oncol Rep. 2019 Jan;41(1):27-42).

106. Xiaoxia X, Jing S, Dongbin X, Yonggang T, Jingke Z, Yanying Z, Hulai W. Realgar nanoparticles inhibit migration, invasion and metastasis in a mouse model of breast cancer by suppressing matrix metalloproteinases and angiogenesis. Curr Drug Deliv. 2020;17(2):148-58. https://doi. org/10.2174/1567201817666200115105633.

107. Zhao QH, Zhang Y, Liu Y, Wang HL, Shen YY, Yang WJ, Wen LP. Anticancer effect of realgar nanoparticles on mouse melanoma skin cancer in vivo via transdermal drug delivery. Med Oncol. 2010;27(2):203-12. https:// doi.org/10.1007/s12032-009-9192-1 (Epub 2009 Mar 12).

108. Zhao WL, Yi Z, Huang QW, Zhou JL, Chen SL. Research on revision of origins to Chinese medicinal materials in 2020 edition of Chinese pharmacopoeia. Zhongguo Zhong Yao Za Zhi. 2021;46(10):2617-22. https:// doi.org/10.19540/j.cnki.cjcmm.20210226.104 (Chinese).

109. Liu J, Wei LX, Wang Q, Lu YF, Zhang F, Shi JZ, Li C, Cherian MG. A review of cinnabar (HgS) and/or realgar (As4S4)-containing traditional medicines. J Ethnopharmacol. 2018;10(210):340-50. https://doi.org/10. 1016/j.jep.2017.08.037 (Epub 2017 Aug 31).

110. Lu YF, Yan JW, Wu Q, Shi JZ, Liu J, Shi JS. Realgar- and cinnabar-containing an-gong-niu-huang wan (AGNH) is much less acutely toxic than sodium arsenite and mercuric chloride. Chem Biol Interact. 2011;189(12):134-40. https://doi.org/10.1016/j.cbi.2010.11.006 (Epub 2010 Nov 19).

111. Li A, Zhang JY, Xiao X, Wang SS, Wan JB, Chai YS, Li P, Wang YT. Hepatorenal protective effects of medicinal herbs in An-Gong-Niu-Huang Wan (AGNH) against cinnabar- and realgar-induced oxidative stress and inflammatory damage in mice. Food Chem Toxicol. 2018;1 19:445-56. https://doi.org/10.1016/j.fct.2017.11.054 (Epub 2017 Dec 2).

112. Lv L, Zheng J, Zhang Y, Chen B, Yan F, Qin X, Zheng C, Wu Z, Feng K. Respiratory nursing care with Angong Niuhuang pill for patients with chronic obstructive pulmonary disease following cardiac surgery. Jpn J Nurs Sci. 2021;18(1):e12344. https://doi.org/10.1111/jjns.12344 (Epub 2020 Sep 13).

113. Chai Y, Yin Z, Fan $Q$, Zhang Z, Ye K, Xu Y, Xiao W, Chai X, Zhu T, Nie H. Protective effects of angong niuhuang pill on early atherosclerosis in ApoE-/ - mice by reducing the inflammatory response. Evid Based Complement Alternat Med. 2019;20(2019):9747212. https://doi.org/10. 1155/2019/9747212.

114. Yang M, Wang L, Zhang T, Zhu A, Sun Y, Zhao J, Liu D, Wang Q, Zeng K. Different proteomic profiles of cinnabar upon therapeutic and toxic exposure reveal distinctive biological manifestations. J Ethnopharmacol. 2020;10(253):112668. https://doi.org/10.1016/j.jep.2020.112668 (Epub 2020 Feb 14).

115. Tsoi B, Wang S, Gao C, Luo Y, Li W, Yang D, Yang D, Shen J. Realgar and cinnabar are essential components contributing to neuroprotection of Angong Niuhuang Wan with no hepatorenal toxicity in transient ischemic brain injury. Toxicol Appl Pharmacol. 2019;377:114613. https:// doi.org/10.1016/j.taap.2019.114613 (Epub 2019 Jun 14).

116. Chen C, Zhang BB, Hu AL, Li H, Liu J, Zhang F. Protective role of cinnabar and realgar in Hua-Feng-Dan against LPS plus rotenone-induced neurotoxicity and disturbance of gut microbiota in rats. J Ethnopharmacol. 2020;247:112299. https://doi.org/10.1016/j.jep.2019.112299 (Epub 2019 Oct 10).

117. Wang Y, Zhou S, Ma H, Shi JS, Lu YF. Investigation of the differential transport mechanism of cinnabar and mercury containing compounds. Environ Toxicol Pharmacol. 2019;66:83-90. https://doi.org/10.1016/j. etap.2018.12.020 (Epub 2018 Dec 26). 
118. Lu YT, Qi WZ, Wang S, Song XN, Yang DY, Song M, Hang TJ. Toxicity and risk assessment of mercury exposures from cinnabar and Baiz Yangxin Pills based on pharmacokinetic and tissue distribution studies. J Ethnopharmacol. 2020;250:112489. https://doi.org/10.1016/j.jep.2019. 112489 (Epub 2019 Dec 19).

119. Liu D, Li J, Wang C, An L, Lin J, Tian Q, Yang S. Ultrasmall Fe@Fe $\mathrm{O}_{4}$ nanoparticles as T1-T2 dual-mode MRI contrast agents for targeted tumor imaging. Nanomedicine. 2021;32: 102335. https://doi.org/10.1016/j. nano.2020.102335 (Epub 2020 Nov 19).

120. Zhang L, Liu L, Zhan S, Chen L, Wang Y, Zhang Y, Du J, Wu Y, Gu L. Arsenic trioxide suppressed migration and angiogenesis by targeting FOXO3a in gastric cancer cells. Int J Mol Sci. 2018;19(12):3739. https:// doi.org/10.3390/ijms19123739.

121. Kim SH, Yoo HS, Joo MK, Kim T, Park JJ, Lee BJ, Chun HJ, Lee SW, Bak YT. Arsenic trioxide attenuates STAT-3 activity and epithelial-mesenchymal transition through induction of SHP-1 in gastric cancer cells. BMC Cancer. 2018;18(1):150. https://doi.org/10.1186/s12885-018-4071-9.

122. Zhang F, Duan J, Song H, Yang L, Zhou M, Wang X. Combination of canstatin and arsenic trioxide suppresses the development of hepatocellular carcinoma. Drug Dev Res. 2021;82(3):430-9. https://doi.org/10.1002/ ddr.21766 (Epub 2020 Nov 27).

123. Wang G, Zhang T, Sun W, Wang H, Yin F, Wang Z, Zuo D, Sun M, Zhou Z, Lin B, Xu J, Hua Y, Li H, Cai Z. Arsenic sulfide induces apoptosis and autophagy through the activation of ROS/JNK and suppression of Akt/mTOR signaling pathways in osteosarcoma. Free Radic Biol Med. 2017;106:24-37. https://doi.org/10.1016/j.freeradbiomed.2017.02.015 (Epub 2017 Feb 7)

124. Zhao Y, Zhao X, Cheng Y, Guo X, Yuan W. Iron oxide nanoparticles-based vaccine delivery for cancer treatment. Mol Pharm. 2018;15(5):1791-9. https://doi.org/10.1021/acs.molpharmaceut.7b01103 (Epub 2018 Mar 23).

125. Zhang Y, Shen L, Wang P, Xi W, Yu Z, Huang X, Wang X, Shou D. Treatment with vancomycin loaded calcium sulphate and autogenous bone in an improved rabbit model of bone infection. J Vis Exp. 2019;(145). https://doi.org/10.3791/57294

126. He Q, Ma J, Kalavagunta PK, Zhou L, Zhu J, Dong J, Ahmad O, Du Y, We $\mathrm{L}$, Shang J. HgS inhibits oxidative stress caused by hypoxia through regulation of 5-HT metabolism pathway. Int J Mol Sci. 2019;20(6):1364. https://doi.org/10.3390/ijms20061364.

127. Kaplan A, Kutlu HM, Ciftci GA. $\mathrm{Fe}_{3} \mathrm{O}_{4}$ nanopowders: genomic and apoptotic evaluations on A549 lung adenocarcinoma cell line. Nutr Cancer. 2020;72(4):708-21. https://doi.org/10.1080/01635581.2019.1643031 (Epub 2019 Jul 23)

128. Yan L, Liu X, Liu WX, Tan XQ, Xiong F, Gu N, Hao W, Gao X, Cao JM. Fe $\mathrm{O}_{3}$ nanoparticles suppress $\mathrm{Kv} 1.3$ channels via affecting the redox activity of Kvß2 subunit in Jurkat T cells. Nanotechnology. 2015;26(50):505103. https://doi.org/10.1088/0957-4484/26/50/505103 (Epub 2015 Nov 20).

129. Ikarashi N, Ogiue N, Toyoda E, Kon R, Ishii M, Toda T, Aburada T, Ochiai W, Sugiyama K. Gypsum fibrosum and its major component $\mathrm{CaSO}_{4}$ increase cutaneous aquaporin-3 expression levels. J Ethnopharmacol. 2012;139(2):409-13. https://doi.org/10.1016/j.jep.2011.11.025 (Epub 2011 Nov 25).

130. Zhang Z, Zhang $F$, Zhang $H$. In vitro response of immune cells on metal oxide nanoparticles with different solubility. J Nanosci Nanotechnol. 2016;16(6):5546-52. https://doi.org/10.1166/jnn.2016.11751.

131. Rajiv S, Jerobin J, Saranya V, Nainawat M, Sharma A, Makwana P, Gayathri C, Bharath L, Singh M, Kumar M, Mukherjee A, Chandrasekaran N Comparative cytotoxicity and genotoxicity of cobalt (II, III) oxide, iron (III) oxide, silicon dioxide, and aluminum oxide nanoparticles on human lymphocytes in vitro. Hum Exp Toxicol. 2016;35(2):170-83. https://doi. org/10.1177/0960327115579208 (Epub 2015 Mar 31).

132. Li X, Liu YF, Xiang XR, Zhou YB, Zhang ZL. Comparative study of the effects of gypsum fibrosum and gypsum fibrosum preparatum in promoting granulation. Zhong Xi Yi Jie He Xue Bao. 2006;4(6):624-7. https://doi.org/10.3736/jcim20060617 (Chinese)

133. Han Z, Song L, Qi K, Ding Y, Wei M, Jia Y. Deciphering the key pharmacological pathways and targets of yisui qinghuang powder that acts on myelodysplastic syndromes using a network pharmacology-based strategy. Evid Based Complement Alternat Med. 2020;8(2020):8877295. https://doi.org/10.1155/2020/8877295.
134. Gong J, Zheng S, Zhang L, Wang Y, Meng J. Induction of K562 Cell apoptosis by As4S4 via down-regulating miR181. Med Sci Monit. 2017;10(23):144-50. https://doi.org/10.12659/msm.899214.

135. Song $X$, You J, Shao H, Yan C. Effects of surface modification of As2O3loaded PLGA nanoparticles on its anti-liver cancer ability: an in vitro and in vivo study. Colloids Surf B Biointerfaces. 2018;1 (169):289-97. https:// doi.org/10.1016/j.colsurfb.2018.05.024 (Epub 2018 May 21).

136. Song P, Chen P, Wang D, Wu Z, Gao Q, Wang A, Zhu R, Wang Y, Wang X, Zhao L, Duan Z, Zhu S, Cui P, Li Y, Li H. Realgar transforming solution displays anticancer potential against human hepatocellular carcinoma HepG2 cells by inducing ROS. Int J Oncol. 2017;50(2):660-70. https:// doi.org/10.3892/ijo.2016.3831 (Epub 2016 Dec 30).

137. Qin YU, Wang H, Liu ZY, Liu J, Wu JZ. Realgar quantum dots induce apoptosis and necrosis in HepG2 cells through endoplasmic reticulum stress. Biomed Rep. 2015;3(5):657-62. https://doi.org/10.3892/br.2015. 489 (Epub 2015 Jul 15).

138. Cao H, Feng Y, Chen L. Repression of MicroRNA-372 by arsenic sulphide inhibits prostate cancer cell proliferation and migration through regulation of large tumour suppressor kinase 2. Basic Clin Pharmacol Toxicol. 2017;120(3):256-63. https://doi.org/10.1111/bcpt.12687 (Epub 2016 Dec 28).

139. Zhang X, Kang T, Zhang L, Tong Y, Ding W, Chen S. NFATc3 mediates the sensitivity of gastric cancer cells to arsenic sulfide. Oncotarget. 2017:8(32):52735-45. https://doi.org/10.18632/oncotarget.17175.

140. Tan Z, Zhang X, Kang T, Zhang L, Chen S. Arsenic sulfide amplifies JQ1 toxicity via mitochondrial pathway in gastric and colon cancer cells. Drug Des Devel Ther. 2018;14(12):3913-27. https://doi.org/10.2147/ DDDT.S180976.

141. Zhao Y, Yuan B, Onda K, Sugiyama K, Tanaka S, Takagi N, Hirano T. Anticancer efficacies of arsenic disulfide through apoptosis induction, cell cycle arrest, and pro-survival signal inhibition in human breast cancer cells. Am J Cancer Res. 2018;8(3):366-86.

142. Yousefi B, Semnani V, Mokhtari T, Zarbakhsh S, Amjad MHT, Barati M, Doustmohammadi H. Co-administration of aluminum sulfate and propolis regulates matrix metalloproteinases-2/9 expression and improves the uterine leiomyoma in adult rat model. Biol Trace Elem Res. 2021;199(3):1002-12. https://doi.org/10.1007/s12011-020-02200-0 (Epub 2020 Jun 27).

143. Pan W, Cai S, Latour JM, Zhong M, Lv M, Li J, Zhang X, Zhang Y. External use of Mirabilite combined with Lactulose improves postoperative gastrointestinal mobility among older patients undergoing abdominal surgery. J Adv Nurs. 2021;77(2):755-62. https://doi.org/10.1111/jan. 14640 (Epub 2020 Nov 24).

144. Chang CJ, Yang YH, Chen PC, Peng HY, Lu YC, Song SR, Yang HY. Stomach cancer and exposure to talc powder without asbestos via Chinese herbal medicine: a population-based cohort study. Int J Environ Res Public Health. 2019;16(5):717. https://doi.org/10.3390/ijerph16050717.

\section{Publisher's Note}

Springer Nature remains neutral with regard to jurisdictional claims in published maps and institutional affiliations.

Ready to submit your research? Choose BMC and benefit from:

- fast, convenient online submission

- thorough peer review by experienced researchers in your field

- rapid publication on acceptance

- support for research data, including large and complex data types

- gold Open Access which fosters wider collaboration and increased citations

- maximum visibility for your research: over 100M website views per year

At BMC, research is always in progress.

Learn more biomedcentral.com/submissions 